\title{
əChanges in Global Ocean Bottom Properties and Volume Transports in CMIP5 Models under Climate Change Scenarios*
}

\author{
CÉline HeuZÉ AND KARen J. Heywood \\ Centre for Ocean and Atmospheric Sciences, School of Environmental Sciences, University of East Anglia, \\ Norwich, United Kingdom \\ DAVID P. STEVENS \\ Centre for Ocean and Atmospheric Sciences, School of Mathematics, University of East Anglia, \\ Norwich, United Kingdom \\ JEFF K. RIDLEY \\ Met Office Hadley Centre, Exeter, United Kingdom
}

(Manuscript received 29 May 2014, in final form 10 November 2014)

\begin{abstract}
Changes in bottom temperature, salinity, and density in the global ocean by 2100 for CMIP5 climate models are investigated for the climate change scenarios RCP4.5 and RCP8.5. The mean of 24 models shows a decrease in density in all deep basins, except the North Atlantic, which becomes denser. The individual model responses to climate change forcing are more complex: regarding temperature, the 24 models predict a warming of the bottom layer of the global ocean; in salinity, there is less agreement regarding the sign of the change, especially in the Southern Ocean. The magnitude and equatorward extent of these changes also vary strongly among models. The changes in properties can be linked with changes in the mean transport of key water masses. The Atlantic meridional overturning circulation weakens in most models and is directly linked to changes in bottom density in the North Atlantic. These changes are the result of the intrusion of modified Antarctic Bottom Water, made possible by the decrease in North Atlantic Deep Water formation. In the Indian, Pacific, and South Atlantic Oceans, changes in bottom density are congruent with the weakening in Antarctic Bottom Water transport through these basins. The authors argue that the greater the 1986-2005 meridional transports, the more changes have propagated equatorward by 2100 . However, strong decreases in density over $100 \mathrm{yr}$ of climate change cause a weakening of the transports. The speed at which these property changes reach the deep basins is critical for a correct assessment of the heat storage capacity of the oceans as well as for predictions of future sea level rise.
\end{abstract}

\section{Introduction}

The bottom of the global ocean is filled with water which sank around Antarctica or in the North Atlantic (Johnson 2008). Long thought to take centuries to react

\section{Denotes Open Access content.}

* Supplemental information related to this paper is available at the Journals Online website: http://dx.doi.org/10.1175/JCLI-D-14-00381.s1.

Corresponding author address: Céline Heuzé, COAS, School of Environmental Sciences, University of East Anglia, Norwich Research Park, Norwich NR4 7TJ, United Kingdom.

E-mail: c.heuze@uea.ac.uk to a surface change, there is evidence that these bottom waters are starting to be modified by climate change. In the Southern Ocean, a warming and loss of density of Antarctic Bottom Water (AABW) have been detected in the Weddell Sea and Atlantic sector for 25 years (Coles et al. 1996), albeit with a significant decadal variability (Fahrbach et al. 2004), and in the Pacific sector since the 1990s (Johnson et al. 2007). In the Weddell Sea, AABW is freshening in response to the melting of ice shelves of the eastern side of the Antarctic Peninsula (Jullion et al. 2013), and so are the shelf waters (Hellmer et al. 2011), probably because of an increase in precipitation and sea ice retreat. In the Australian-Antarctic basin, bottom waters are rapidly freshening and becoming less dense, probably because 
of the changes in high-latitude freshwater balance (Rintoul 2007), especially the melting of glaciers in the Amundsen Sea (Bindoff and Hobbs 2013). Purkey and Johnson (2010) have shown that property changes can be detected in the North Pacific and Atlantic basins and that bottom water changes play a crucial role regarding heat storage and sea level rise: the abyssal warming since the 1990s is responsible for an increase in mean global sea level of $0.053 \mathrm{~mm} \mathrm{yr}^{-1}$.

Phase 5 of the Climate Model Intercomparison Project (CMIP5) is an international collaboration providing a multimodel context to help understand the responses of climate models to a common forcing (Taylor et al. 2012). It aims at facilitating climate model assessment and projections for the Fifth Assessment Report (AR5) of the Intergovernmental Panel on Climate Change (IPCC). Its goal, among other things, is to predict future climate and sea level rise in a warming world (Stocker et al. 2014).

The model parameterization of vertical mixing processes accounts for a large part of the spread in projected thermosteric sea level rise (Kuhlbrodt and Gregory 2012), with the greatest ocean heat uptake by waters below $2000 \mathrm{~m}$ taking place in the Southern Ocean. A study of the Southern Ocean water masses in the CMIP5 model projections indicates that the largest warming is in the intermediate and mode waters (Sallée et al. 2013). A characteristic of the CMIP5 models that may influence the heat uptake and deep water mass characteristics is that they form much of their AABW by open ocean deep convection in the subpolar gyres of the Southern Ocean rather than through off-shelf flow (Heuzé et al. 2013). Models build up heat at middepth, which eventually melts the winter sea ice: the resulting heat loss to the atmosphere and brine rejection causes open ocean deep convection (Martin et al. 2013). This process is expected to cease in climate change simulations because of an increase in salinity stratification of the Southern Ocean (de Lavergne et al. 2014). It is possible that long-term changes in the large scale circulation of the climate models, either through changes to the Atlantic meridional overturning circulation (AMOC; Dickson et al. 2002) or the Antarctic Circumpolar Current (ACC; Meijers et al. 2012), may influence the properties of the modeled deep water masses (Jia 2003). Such changes to the deep water masses have implications for projected ocean heat uptake and sea level rise.

Here we present an analysis of the CMIP5 models to identify the range of responses of the global abyssal water masses to climate change. We investigate the relationship between the future deep ocean property changes and the deep and bottom water Eulerian transports and circulations in CMIP5 models. Section 2 features a brief description of the models and outputs we use, as well as a description of the calculation of transport of deep and bottom waters. Section 3 presents our results, split into three parts: first bottom property changes in CMIP5 models by the end of the twenty-first century; then AMOC, ACC, and AABW transport values and changes in the models; and finally the relationships between bottom property changes and both the mean absolute values and the changes in transports, first in the Southern Hemisphere and then in the North Atlantic (mostly in relation to the AMOC). In section 4, we discuss these relationships, showing that the magnitude of the meridional volume transport determines the changes in bottom properties, which in turn induce a change in transports. The limitations of our study and ideas for future model development are also presented in section 4 . Section 5 contains a summary of our results as well as concluding remarks regarding the importance of these findings for the climate system.

\section{Data and methods}

\section{a. CMIP5 models}

We used the output of 25 CMIP5 models, which are listed in Table 1 (one model will subsequently be excluded, as discussed later). For all models we considered only their first ensemble member: at the date of the download (August 2013), it was the only one available for all the experiments for over half of the models we study. As is standard for CMIP5 studies (Flato et al. 2014), we averaged the properties over the last $20 \mathrm{yr}$ of the historical run (1986-2005) and the last $20 \mathrm{yr}$ of the climate change scenarios (2081-2100). The climate change scenarios or representative concentration pathways (RCPs) used here are RCP4.5 and RCP8.5, corresponding to a top of the atmosphere radiative imbalance of 4.5 and $8.5 \mathrm{~W} \mathrm{~m}^{-2}$ by 2100 , respectively (Taylor et al. 2012). Model drift was removed by subtracting the mean preindustrial control corresponding to 1986-2005 and 2081-2100 from the historical and climate change scenarios values, respectively. We then assume that the change in ocean properties is due to the climate change forcing. A comparison of the climate change signal with the model drift is given in the appendix, showing that over the period we consider this assumption is reasonable.

Shared model components may lead to shared biases but also similar responses (Flato et al. 2014). To investigate the distinct role of the atmosphere and the ocean as well as the impact of resolution, we have included in our sample models that share components: 
TABLE 1. CMIP5 models used in this study: name, ocean vertical coordinate type ( $z, z^{*}$, isopycnic, or sigma level) and number of ocean vertical levels, average horizontal resolution (latitude $\times$ longitude), and reference. Only one number is indicated for the horizontal resolution if the latitude and longitude have the same resolution. Note that INM-CM4 is not included in the multimodel analyses. (Expansion of model name acronyms are available online at http://www.ametsoc.org/PubsAcronymList.)

\begin{tabular}{|c|c|c|c|}
\hline Model name & Vertical grid & Horizontal resolution & Reference \\
\hline ACCESS1.0 & $z 50$ & $1^{\circ}-0.3^{\circ}$ & Bi et al. (2013) \\
\hline BCC_CSM1.1 & $z 40$ & $1^{\circ}-0.3^{\circ}$ & Xin et al. (2013) \\
\hline CanESM2* & $z 40$ & $1.5^{\circ}$ & Arora et al. (2011) \\
\hline CCSM4 & $z 60$ & $0.5^{\circ} \times 1^{\circ}$ & Danabasoglu et al. (2012) \\
\hline CESM1 (CAM5) & $z 60$ & $0.5^{\circ} \times 1^{\circ}$ & Danabasoglu et al. (2012) \\
\hline $\mathrm{CMCC}-\mathrm{CM}$ & $z 31$ & $2^{\circ}$ & Fogli et al. (2009) \\
\hline CMCC-CMS & z 31 & $2^{\circ}$ & Fogli et al. (2009) \\
\hline CNRM-CM5* & $z 42$ & $0.7^{\circ}$ & Voldoire et al. (2013) \\
\hline CSIRO Mk3.6.0* & z 31 & $0.9^{\circ} \times 1.8^{\circ}$ & Gordon et al. (2010) \\
\hline FGOALS-g2 & $z^{*} 30$ & $1^{\circ}$ & Liu et al. (2012) \\
\hline GFDL CM3 & $z^{*} 50$ & $1^{\circ}$ & Griffies et al. (2011) \\
\hline GFDL-ESM2G* & isopycnic 63 & $1^{\circ}$ & Dunne et al. (2012) \\
\hline GFDL-ESM2M* & $z^{*} 50$ & $1^{\circ}$ & Dunne et al. (2012) \\
\hline GISS-E2-H & hybrid $z$-isopycnic 26 & $1^{\circ}$ & Schmidt et al. (2006) \\
\hline GISS-E2-R* & $z^{*} 32$ & $1^{\circ} \times 1.25^{\circ}$ & Schmidt et al. (2006) \\
\hline HadGEM2-CC & $z 40$ & $1^{\circ}-0.3^{\circ}$ & Jones et al. (2011) \\
\hline HadGEM2-ES* & $z 40$ & $1^{\circ}-0.3^{\circ}$ & Jones et al. (2011) \\
\hline INM-CM4* & sigma 40 & $0.5^{\circ} \times 1^{\circ}$ & Volodin et al. (2010) \\
\hline IPSL-CM5A-LR* & z 31 & $2^{\circ}-0.5^{\circ}$ & Dufresne et al. (2013) \\
\hline IPSL-CM5A-MR & z 31 & $2^{\circ}-0.5^{\circ}$ & Dufresne et al. (2013) \\
\hline MIROC5 & hybrid sigma $-z 50$ & $1.4^{\circ}-0.5^{\circ}$ & Watanabe et al. (2011) \\
\hline MIROC-ESM-CHEM* & hybrid sigma $-z$ & $1.4^{\circ}-0.5^{\circ}$ & Watanabe et al. (2011) \\
\hline MPI-ESM-LR* & $z 40$ & $1.5^{\circ}$ & Jungclaus et al. (2013) \\
\hline MPI-ESM-MR & $z 40$ & $0.4^{\circ}$ & Jungclaus et al. (2013) \\
\hline NorESM1-M* & hybrid $z$-isopycnic 53 & $1.125^{\circ}$ & Tjiputra et al. (2013) \\
\hline
\end{tabular}

* Model studied in the appendix.

- ACCESS1.0 has the same atmosphere model code and configuration as HadGEM2 and the same ocean model code as GFDL CM3 and GFDL-ESM2M (but a different configuration).

- CCSM4 and CESM1 (CAM5) have the same ocean model code but use a different atmosphere model code.

- CMCC-CM and CMCC-CMS have the same ocean code and configuration and the same atmosphere code with different configurations.

- GFDL-ESM2G and GFDL-ESM2M share the same atmosphere, land, and sea ice model codes. GFDLESM2M and GFDL CM3 share ocean codes that are roughly the same, whereas their atmosphere codes differ.

- GISS-E2-H and GISS-E2-R have the same atmosphere model code but different oceans.

- HadGEM2-ES is basically HadGEM2-CC with the addition of tropospheric chemistry.

- IPSL-CM5A-LR and IPSL-CM5A-MR have the same ocean and atmosphere model codes, but the resolution of the atmosphere is higher in IPSL-CM5A-MR.

- MIROC5 features a more recent version of the ocean model code than MIROC-ESM-CHEM and a different atmosphere model.
- MPI-ESM-LR and MPI-ESM-MR share the same ocean and atmosphere model codes; however, MPIESM-MR has a higher horizontal resolution in the ocean and vertical resolution in the atmosphere.

We quantified the agreement among models following the procedure adopted in the IPCC AR5 (Collins et al. 2014): we consider as robust areas where at least $66 \%$ of the models (16 models) agree on the sign of the change; these areas will be the focus of this paper. The results from the model INM-CM4 are given as supplementary material but are not included in the multimodel studies, as this model has been proven to be strongly biased (e.g., Meijers et al. 2012; Heuzé et al. 2013; Sallée et al. 2013).

\section{b. Ocean properties and sea level}

For the bottom properties, as the potential density was not directly available for all the models, we computed the potential density relative to $2000 \mathrm{~m}\left(\sigma_{2}\right)$ and relative to the surface $\left(\sigma_{\theta}\right)$ using the equation of state EOS80 (Fofonoff and Millard 1983) from the salinity and potential temperature (hereafter referred to simply as temperature) diagnostics. We chose $\sigma_{2}$ as a compromise to deal with both the shallow continental shelves 
and the deep basins with a single property. Salinity is presented on the practical salinity scale, so it has no unit.

For each model, to study their deep and bottom water formation and ventilation, the monthly mixed layer depth (MLD) was calculated using a density $\sigma_{\theta}$ threshold of $0.03 \mathrm{~kg} \mathrm{~m}^{-3}$ from the $10-\mathrm{m}$ depth value (de Boyer Montégut et al. 2004). The observed MLD in the North Atlantic and Southern Ocean was obtained from the climatology of de Boyer Montégut et al. (2004), using the same density threshold criterion. The sea ice is also shown, as it can have a large impact on the MLD at high latitudes through brine rejection; observations come from the HadISST climatology (Rayner et al. 2003). To see if the property changes are limited to the bottom of the ocean or if they could come from the surface, profiles of the water column in the deep Labrador Sea are averaged over an area of near constant bathymetry (between 3200 and $3500 \mathrm{~m}$ ) to create a mean profile change per model for temperature and salinity. Following the observations by Våge et al. (2009), for example, we consider that there is deep convection in the North Atlantic if the maximum MLD is deeper than $1000 \mathrm{~m}$.

We retained the model native grids, apart for the production of multimodel means where they were interpolated onto the lowest resolution model's grid $\left(1.5^{\circ} \times 1.5^{\circ}\right)$. We defined the bottom properties of the oceans as the properties of the deepest ocean level containing data for each latitude-longitude grid point. For each region studied in this paper (boundaries delimited by yellow lines in Fig. 1c), we calculated the area-weighted mean change in property over the region, as well as the spatial standard deviation of this change in the region.

The steric mean global sea level rise (MGSLR) corresponding to the change in properties in the bottom $500 \mathrm{~m}$ of the deep global ocean (bathymetry $>3000 \mathrm{~m}$ ) can be split into a thermosteric contribution and a halosteric one. Following Purkey and Johnson (2010), the thermosteric part is calculated for each grid cell from the temperature $\theta$ change as

$$
\eta_{T}=\int_{\text {bottom }}^{\text {bottom-500m }} \alpha \frac{d \theta}{d t} d z .
$$

Similarly, we calculated the halosteric part for each grid cell from the salinity $S$ change as

$$
\eta_{S}=\int_{\text {bottom }}^{\text {bottom- } 500 \mathrm{~m}}-\beta \frac{d S}{d t} d z
$$

The thermosteric and halosteric MGSLR are then obtained as the area-weighted mean of $\eta_{T}$ and $\eta_{S}$, respectively. These are compared with the observed current rate of change due to the warming and freshening of bottom waters to see if models are consistent with observations.
They are also compared with the projected sea level rise by 2100 by the IPCC (Collins et al. 2014) to see the contribution of bottom waters relative to the whole water column.

\section{c. Volume transports}

At the time of the download (August 2013), only three models of our study (listed in Table 1) had their streamfunctions or transports through Drake Passage available directly as outputs. For consistency, we instead used the horizontal velocities provided by all the models and computed the volume transports from these velocities.

We calculate the AMOC using the same method as Cheng et al. (2013), who looked at the AMOC for 10 CMIP5 models. We integrate the meridional velocity at $30^{\circ} \mathrm{N}$ through the Atlantic basin from coast to coast. We then integrate this result over depth, from the bottom of the ocean to the surface. We define the AMOC at $30^{\circ} \mathrm{N}$ as the maximum southward transport.

Likewise, we compute the ACC transport by calculating the total transport through Drake Passage. We integrate the zonal velocity from the Antarctic Peninsula to South America. We then integrate this result over depth, from the bottom of the ocean to the surface. We define the ACC transport as the total sum resulting from these integrations.

We are not aware of a previous systematic study of AABW transport through each basin in CMIP models. We compute the deep southern meridional overturning circulation (SMOC) with a method similar to the one for the AMOC. In each basin (Atlantic, Indian, and Pacific) we integrate the meridional velocity at $30^{\circ} \mathrm{S}$ from the basin's west coast to its east coast. As for the other transports, we integrate this result vertically, with the transport at the bottom of the ocean being defined as zero. We are interested in the AABW transport in each basin: that is, a northward transport at the bottom of the ocean. As a consequence, we define our SMOC as the first maximum of this function, from the bottom to $2500-\mathrm{m}$ depth. The value of $2500 \mathrm{~m}$ is arbitrary, but varying this threshold between 2000 and $3000 \mathrm{~m}$ does not affect significantly the value of the SMOC.

This study is thus restricted to the mean or Eulerian transport. Unfortunately, the eddy-induced component of the transports could not be included in this study as the majority of CMIP5 models have not made this output available. Results from four models that made it available showed that the eddy-induced transport is negligible compared with the Eulerian transport for the SMOC at $30^{\circ} \mathrm{S}$ and $\mathrm{AMOC}$ at $30^{\circ} \mathrm{N}$. However, the eddyinduced transport can compensate the mean flow at high latitudes (Downes and Hogg 2013) or even dominate it at decadal and longer time scales (Lee et al. 1997).

To investigate the across-model relationship between Eulerian transports and bottom property changes, 20-yr 

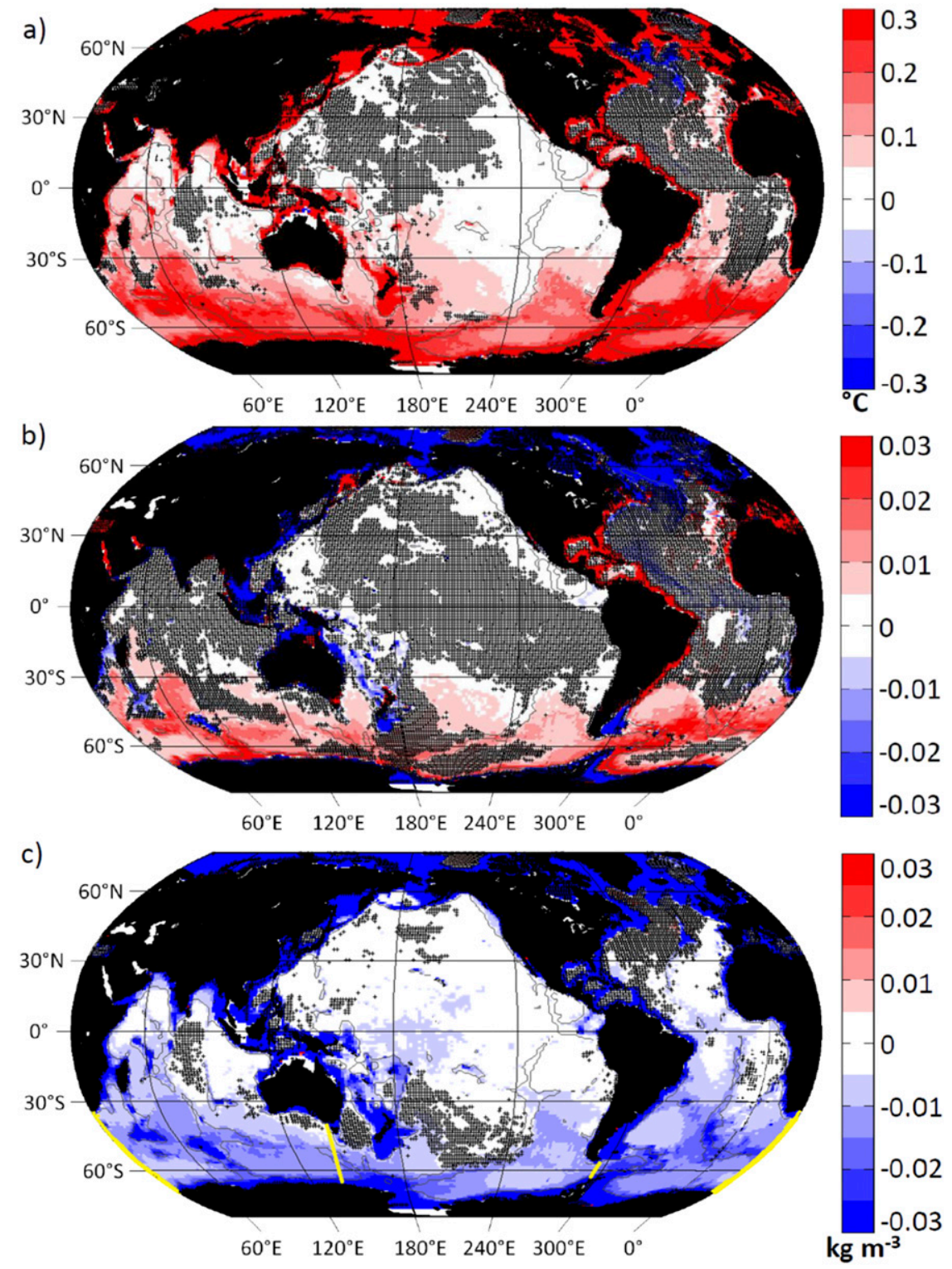

FIG. 1. RCP8.5 multimodel mean change (2081-2100 minus 1986-2005) in (a) bottom temperature, (b) bottom salinity, and (c) bottom density $\sigma_{2}$. Control drift has been removed. Black stippling indicates areas where fewer than 16 models agree on the sign of the change. Gray contour indicates the 3000-m isobath. Yellow lines in (c) indicate the study boundaries for the three ocean basins in the Southern Ocean.

mean transport values are calculated for the historical run (1986-2005) and climate change runs (2081-2100) after removal of the preindustrial control drift, as is done for the bottom property changes. To see if the transports change linearly throughout the twenty-first century or suddenly (and, if suddenly, then when), we also look at the whole 1986-2100 annual mean time series in transports. Hence, in section $3 \mathrm{~b}$ only, we study the annual transport time series and show them as differences from 1986. As is shown in the appendix, it is not sensible to use linear fits for the preindustrial control drift or climate change response. Instead we subtract the control value from the climate change value at each time step. The variability of the annual mean transport in the preindustrial control run from 1986 to 2100 is given in Table 2. Finally, a 15-yr low-pass filter is applied to the Fourier transform of the 1986-2100 dedrifted time series to show the long-term change signal in transports.

For the 24 models, assuming that the bottom property changes may be advected by the bottom flows, we looked 
TABLE 2. Historical (1986-2005) mean and temporal standard deviation of the annual mean over 1986-2100 (preindustrial control run, not filtered) of the transports for the 25 models, and historical multimodel mean and spread: Atlantic meridional overturning circulation; Antarctic Circumpolar Current; and Atlantic Ocean, Indian Ocean, Pacific Ocean, and total bottom southern meridional overturning circulation.

\begin{tabular}{|c|c|c|c|c|c|c|}
\hline Model & AMOC & $\mathrm{ACC}$ & Atlantic SMOC & Indian SMOC & Pacific SMOC & Total SMOC \\
\hline ACCESS1.0 & $19 \pm 1$ & $135 \pm 2$ & $2.5 \pm 0.7$ & $0.7 \pm 0.5$ & $5.2 \pm 1.4$ & $8.4 \pm 1.7$ \\
\hline BCC_CSM1.1 & $16 \pm 1$ & $159 \pm 6$ & $3.7 \pm 1.0$ & $1.9 \pm 0.7$ & $6.6 \pm 1.4$ & $12.2 \pm 1.9$ \\
\hline CanESM2 & $16 \pm 1$ & $154 \pm 2$ & $2.5 \pm 0.8$ & $0.5 \pm 0.2$ & $5.9 \pm 1.1$ & $8.9 \pm 1.3$ \\
\hline CCSM4 & $18 \pm 1$ & $173 \pm 2$ & $1.2 \pm 0.4$ & $1.1 \pm 0.4$ & $1.7 \pm 0.7$ & $4.0 \pm 0.9$ \\
\hline CESM1 (CAM5) & $19 \pm 1$ & $155 \pm 2$ & $1.0 \pm 0.5$ & $0.1 \pm 0.1$ & $0.1 \pm 0.1$ & $1.2 \pm 0.5$ \\
\hline $\mathrm{CMCC}-\mathrm{CM}$ & $13 \pm 1$ & $97 \pm 2$ & $1.5 \pm 0.4$ & $0.3 \pm 0.1$ & $0.7 \pm 0.3$ & $2.6 \pm 0.5$ \\
\hline CMCC-CMS & $15 \pm 1$ & $103 \pm 3$ & $1.0 \pm 0.4$ & $0.5 \pm 0.2$ & $2.1 \pm 0.7$ & $3.6 \pm 0.8$ \\
\hline CNRM-CM5 & $12 \pm 2$ & $83 \pm 4$ & $1.4 \pm 0.6$ & $2.3 \pm 0.4$ & $1.4 \pm 0.7$ & $5.1 \pm 0.9$ \\
\hline CSIRO Mk3.6.0 & $20 \pm 1$ & $110 \pm 2$ & $4.3 \pm 0.5$ & $0.1 \pm 0.1$ & $1.5 \pm 0.6$ & $5.9 \pm 0.8$ \\
\hline FGOALS-g2 & $26 \pm 1$ & $147 \pm 2$ & $3.0 \pm 0.5$ & $1.4 \pm 0.7$ & $17.0 \pm 1.0$ & $21.5 \pm 1.4$ \\
\hline GFDL CM3 & $21 \pm 1$ & $159 \pm 3$ & $3.0 \pm 0.5$ & $0.1 \pm 0.2$ & $0.2 \pm 0.3$ & $3.3 \pm 0.6$ \\
\hline GFDL-ESM2G & $20 \pm 2$ & $106 \pm 2$ & $3.4 \pm 1.2$ & $3.7 \pm 1.6$ & $17.7 \pm 1.0$ & $24.8 \pm 2.2$ \\
\hline GFDL-ESM2M & $19 \pm 1$ & $133 \pm 2$ & $3.3 \pm 0.6$ & $3.0 \pm 1.1$ & $7.7 \pm 1.5$ & $14.0 \pm 2.0$ \\
\hline GISS-E2-R & $21 \pm 2$ & $193 \pm 4$ & $0.6 \pm 0.2$ & $5.4 \pm 0.9$ & $11.1 \pm 1.9$ & $17.1 \pm 2.0$ \\
\hline GISS-E2-H & $18 \pm 1$ & $244 \pm 3$ & $1.5 \pm 0.5$ & $0.2 \pm 0.2$ & $0.4 \pm 0.4$ & $2.1 \pm 0.6$ \\
\hline HadGEM2-CC & $18 \pm 2$ & $179 \pm 19$ & $3.3 \pm 1.5$ & $3.3 \pm 1.2$ & $10.5 \pm 1.7$ & $17.1 \pm 3.1$ \\
\hline HadGEM2-ES & $17 \pm 1$ & $173 \pm 3$ & $3.7 \pm 1.3$ & $3.4 \pm 1.0$ & $9.7 \pm 1.1$ & $16.8 \pm 2.1$ \\
\hline INM-CM4* & $11 \pm 2$ & $318 \pm 6$ & $0.0 \pm 0.0$ & $0.0 \pm 0.0$ & $0.0 \pm 0.0$ & $0.0 \pm 0.0$ \\
\hline IPSL-CM5A-LR & $11 \pm 1$ & $98 \pm 3$ & $3.4 \pm \pm 0.6$ & $4.0 \pm 1.4$ & $8.2 \pm 1.0$ & $15.6 \pm 2.0$ \\
\hline IPSL-CM5A-MR & $14 \pm 2$ & $104 \pm 11$ & $4.5 \pm 0.8$ & $1.9 \pm 1.3$ & $9.0 \pm 1.4$ & $15.4 \pm 2.5$ \\
\hline MIROC5 & $20 \pm 2$ & $225 \pm 3$ & $0.0 \pm 0.0$ & $2.7 \pm 0.8$ & $10.9 \pm 1.3$ & $13.5 \pm 1.6$ \\
\hline MIROC-ESM-CHEM & $13 \pm 1$ & $193 \pm 3$ & $2.8 \pm 0.5$ & $0.2 \pm 0.2$ & $4.8 \pm 0.7$ & $7.8 \pm 0.8$ \\
\hline MPI-ESM-LR & $19 \pm 3$ & $132 \pm 3$ & $2.5 \pm 0.5$ & $0.0 \pm 0.0$ & $3.2 \pm 1.0$ & $5.7 \pm 1.2$ \\
\hline MPI-ESM-MR & $10 \pm 4$ & $181 \pm 4$ & $3.4 \pm 1.9$ & $2.2 \pm 0.5$ & $3.4 \pm 0.9$ & $9.1 \pm 2.1$ \\
\hline NorESM1-M & $32 \pm 1$ & $128 \pm 2$ & $0.2 \pm 0.2$ & $0.1 \pm 0.1$ & $3.4 \pm 2.1$ & $3.7 \pm 2.1$ \\
\hline Multimodel & $18 \pm 5$ & $149 \pm 42$ & $2.4 \pm 1.3$ & $1.6 \pm 1.6$ & $5.9 \pm 5.0$ & $10.0 \pm 6.7$ \\
\hline
\end{tabular}

* INM-CM4 is not included in the multimodel means, as explained in the text.

for correlations between the transports (mean 19862005 value, mean 2081-2100 value, and dedrifted changes by 2100) and the dedrifted changes in bottom properties. We performed a Student's $t$ test to check if the correlation relationships were significant ( $p$ value $<$ 0.05), following for example Levitus et al. (2000). Multimodel mean changes and transports are also indicated: these correspond to the nonweighted mean of the 24 models. Variations among models are indicated by standard deviations or graphically through model spread.

\section{Results}

\section{a. Bottom property changes}

Most models predict a strong warming of the shelf regions where water depth is shallower than $1000 \mathrm{~m}$ (Fig. 1a). This warming is on average $2.3^{\circ} \pm 1.0^{\circ} \mathrm{C}$ (spatial variation) in the Arctic north of $60^{\circ} \mathrm{N}$ and $0.6^{\circ} \pm$ $0.2^{\circ} \mathrm{C}$ in the Antarctic south of $60^{\circ} \mathrm{S}$. Although the Antarctic shelf warming is less strong than the Arctic, it has a strong effect on the marine-based Antarctic ice sheets (Yin et al. 2011). All models agree on a warming of the deep Southern Ocean $\left(0.19^{\circ} \pm 0.07^{\circ} \mathrm{C}\right.$ on average for the whole area south of $50^{\circ} \mathrm{S}$ ) and more than 16 models present a warming in the whole deep Southern Hemisphere apart from the Angola basin and the Louisville seamount chain (southwest Pacific). We hypothesize that the warming of the Southern Ocean in CMIP5 models is due to the way they form their Antarctic Bottom Water. In the real ocean, bottom water formation takes place on the shelves and then waters spill off into the deep ocean, so the mixed layer is relatively shallow in the subpolar gyres (Fig. 2a). In CMIP5 models, AABW is formed by open ocean deep convection in the Weddell and Ross gyres (Fig. 3). The warming observed in the bottom waters may originate from the surface of the Southern Ocean and has been carried to the bottom by deep convection. In our study, 19 models have some deep convection over 1986-2005 (Fig. 3). Although during 2081-2100 most models have a decreased convective area, only four models have stopped deep convection by 2100 (Fig. 4). We found significant correlations between the bottom temperature changes in the Southern Ocean and the 1986-2005 area of deep convection: the more extensively the model 
a)
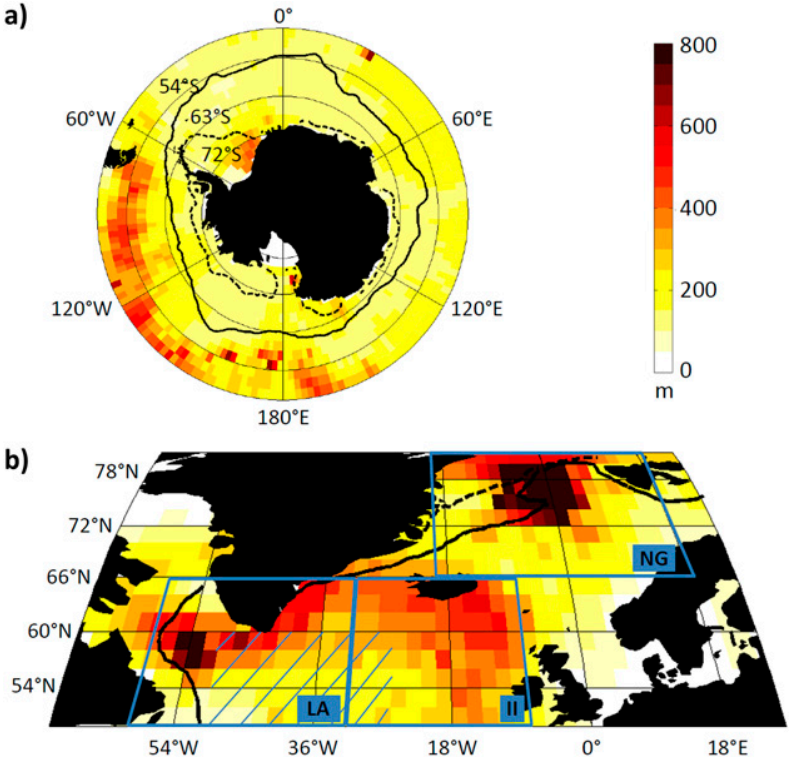

FIG. 2. Observed winter mixed layer depth (shading) from the climatology of de Boyer Montégut et al. (2004) (updated in November 2008), calculated using a $\sigma_{\theta}$ threshold of $0.03 \mathrm{~kg} \mathrm{~m}^{-3}$ compared with 10-m depth, for (a) the Southern Ocean south of $50^{\circ} \mathrm{S}$ and (b) the North Atlantic. Black lines indicate the mean observed winter sea ice extent (plain line) and the mean observed summer sea ice extent (dashed line), from the HadISST observations (Rayner et al. 2003). The three convective areas for section $3 \mathrm{~d}$ are indicated by blue boxes in (b): Labrador Sea, Irminger and Iceland basins, and Norwegian and Greenland Seas. Hatching in the LA and II boxes indicates the area used for the calculation of the mean profile changes in section $3 \mathrm{~d}$ and Fig. 10.

convects, the more the bottom of the Southern Ocean has warmed by 2100 .

There is little temperature change in the North $\mathrm{Pa}$ cific, while the North Atlantic cools south of Greenland (mean of $-0.22^{\circ} \pm 0.18^{\circ} \mathrm{C}$ ). INM-CM4, not included in the multimodel mean, is the only model which projects a cooling of the whole Atlantic and Southern Oceans (supplementary Fig. S1c). All other models agree on a warming of the deep oceans, but the equatorward extent of this warming, especially in the Pacific, strongly differs from one model to another. For instance, the warming is still clear north of the equator in the Pacific for GFDL-ES2G (Fig. 51), whereas the warming is weak, even in the South Pacific, for CNRM-CM5 (Fig. 5g). The same occurs in the North Atlantic: although all models agree on a cooling, this cooling does not occur at the same place for all of them, explaining the apparent disagreement in the multimodel mean (Fig. 1a).

The multimodel mean change in bottom salinity (Fig. 1b) is more complex and presents less agreement among models than that for temperature. Both the Arctic and Antarctic shelves freshen $(-0.41 \pm 0.30$ in the Arctic; $-0.10 \pm 0.08$ in Antarctica). Most models have a fresher North Atlantic south of Greenland $(-0.03 \pm 0.03)$ and a saltier deep Southern Hemisphere $(0.02 \pm 0.01$ on average for the whole Southern Hemisphere) with the exception of the central Ross and Weddell Seas, where little agreement among models leads to a mean change around zero. One major feature appears when looking at the models separately (Fig. 6): 12 models become saltier in the whole Southern Ocean (ACCESS1.0 (Fig. 6a), CCSM4 (Fig. 6d), CNRM-CM5 (Fig. 6h), the three GFDL models (Figs. 6k-m), the two HadGEM2 models (Figs. 6p,q), MIROC5 (Fig. 6t), the two MPI-ESM models (Figs. 6v,w), and NorESM1-M (Fig. 6x)], 5 models become saltier only in the Weddell Basin but freshen in the Ross Basin [CMCC-CMS (Fig. 6g), GISS-E2-R (Fig. 6o), the two IPSL-CM5A models (Figs. 6r,s), and MIROC-ESM-CHEM (Fig. 6u)], 3 models freshen in the Weddell Basin but become saltier in the Ross Basin [CESM1 (CAM5) (Fig. 6e), CMCC-CM (Fig. 6f), and CSIRO Mk3.6.0 (Fig. 6i)], and the last 4 models freshen in both basins [BCC_CSM1.1(m) (Fig. 6b), CanESM2 (Fig. 6c), FGOALS-g2 (Fig. 6j), and GISS-E2-H (Fig. 6n)]. We found no consistent link between the changes in salinity in the Southern Ocean and deep convection: for example, both CMCC models convect in the Weddell Sea during 1986-2005 (Figs. 3f,g) and 2081-2100 (Figs. 4f,g), but CMCC-CMS becomes saltier in the Weddell Sea (Fig. 6g), whereas CMCC-CM freshens there (Fig. 6f). Likewise, no significant link could be found with changes in sea ice concentration or in the hydrological cycle over the regions (not shown). No consistent link was found either with the results of Wang (2013) regarding the Weddell and Ross gyre strength in CMIP5 models. For instance, Wang found that MIROC-ESMCHEM gyre strength decreases in both the Weddell and the Ross Seas during the climate change run, whereas we found it becomes saltier in the Weddell Sea but fresher in the Ross Sea (Fig. 6u). Similarly, we found no link with the subpolar and subtropical gyre circulation changes studied by Meijers et al. (2012). GFDL-ESM2G and NorESM1-M both become saltier throughout the deep Southern Ocean (Figs. 61,x), but the subpolar gyre strength increases for GFDL-ESM2G and decreases for NorESM1-M, whereas the subtropical gyre strength decreases for GFDL-ESM2G and increases for NorESM1-M.

The multimodel changes in bottom density (Fig. 1c) are dominated by the changes in temperature and hence present quite similar patterns: the Arctic and Antarctic shelves and the deep Southern Hemisphere basins become lighter $(-0.62 \pm 0.27,-0.14 \pm 0.07$, and $-0.011 \pm$ $0.006 \mathrm{~kg} \mathrm{~m}^{-3}$, respectively). The North Atlantic south of Greenland hardly becomes denser because of its strong 

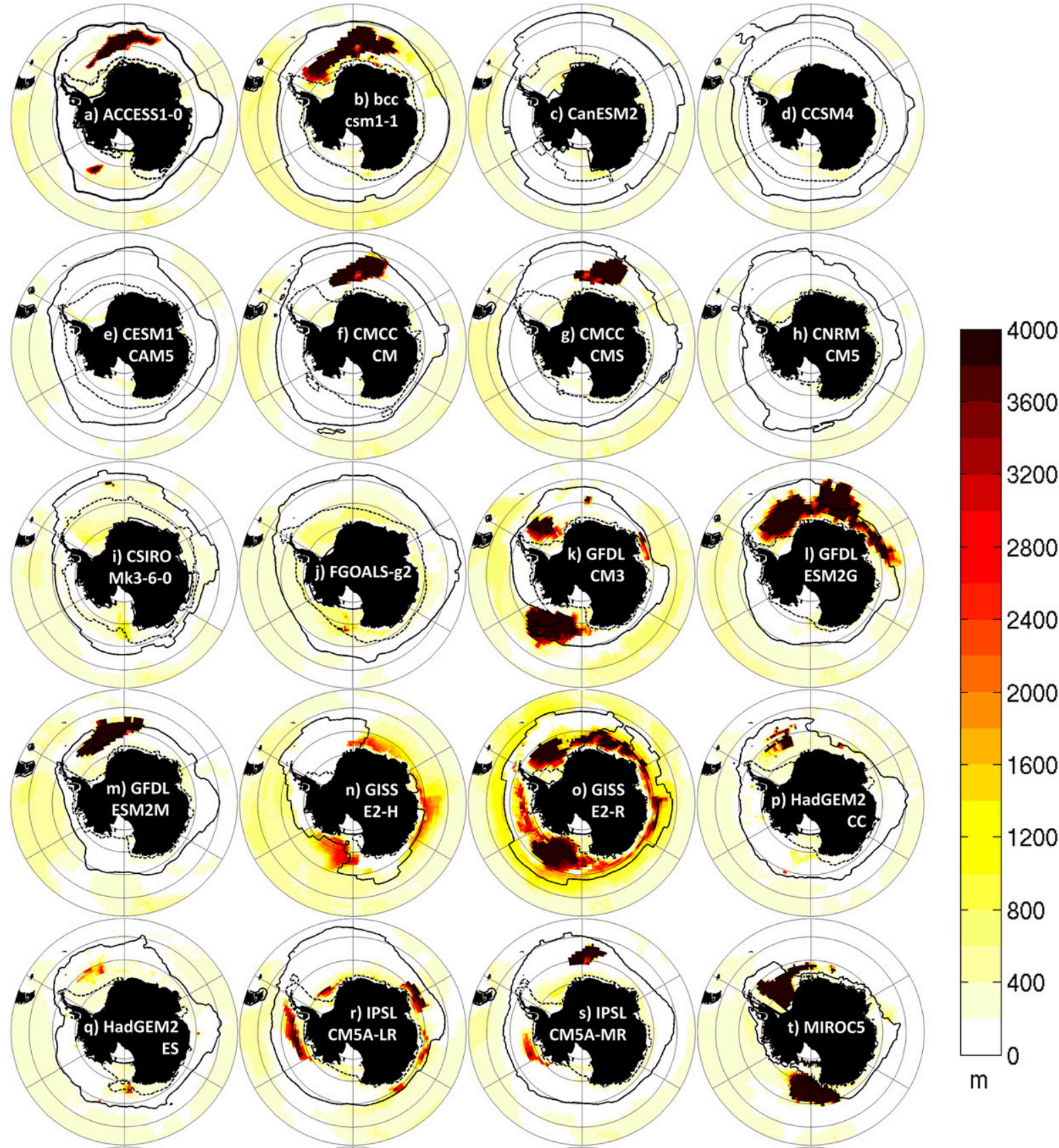

$\mathrm{m}$
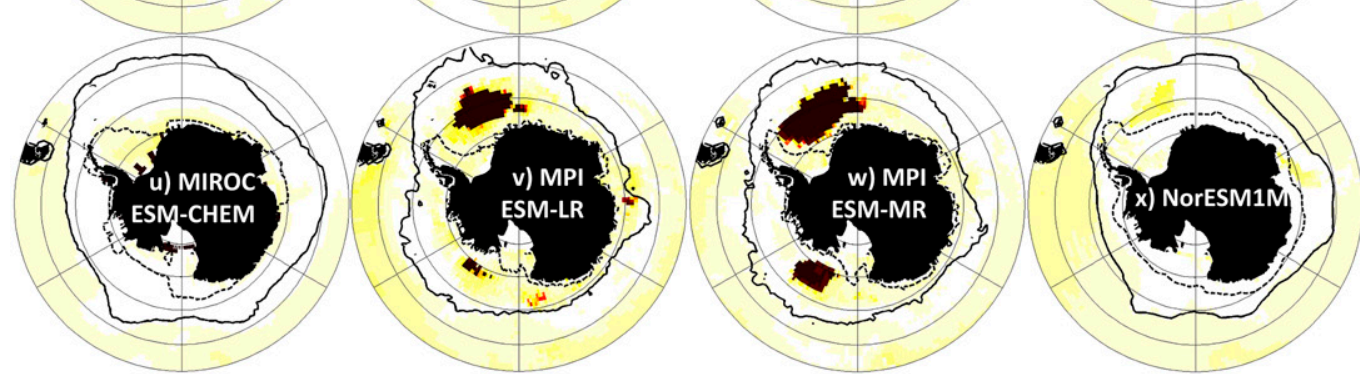

FIG. 3. Southern Ocean historical (1986-2005) maximum depth of the mixed layer in any month of the 20 years, for each model and each grid cell. Black lines indicate the mean August sea ice extent (plain line) and the mean February sea ice extent (dashed line). 

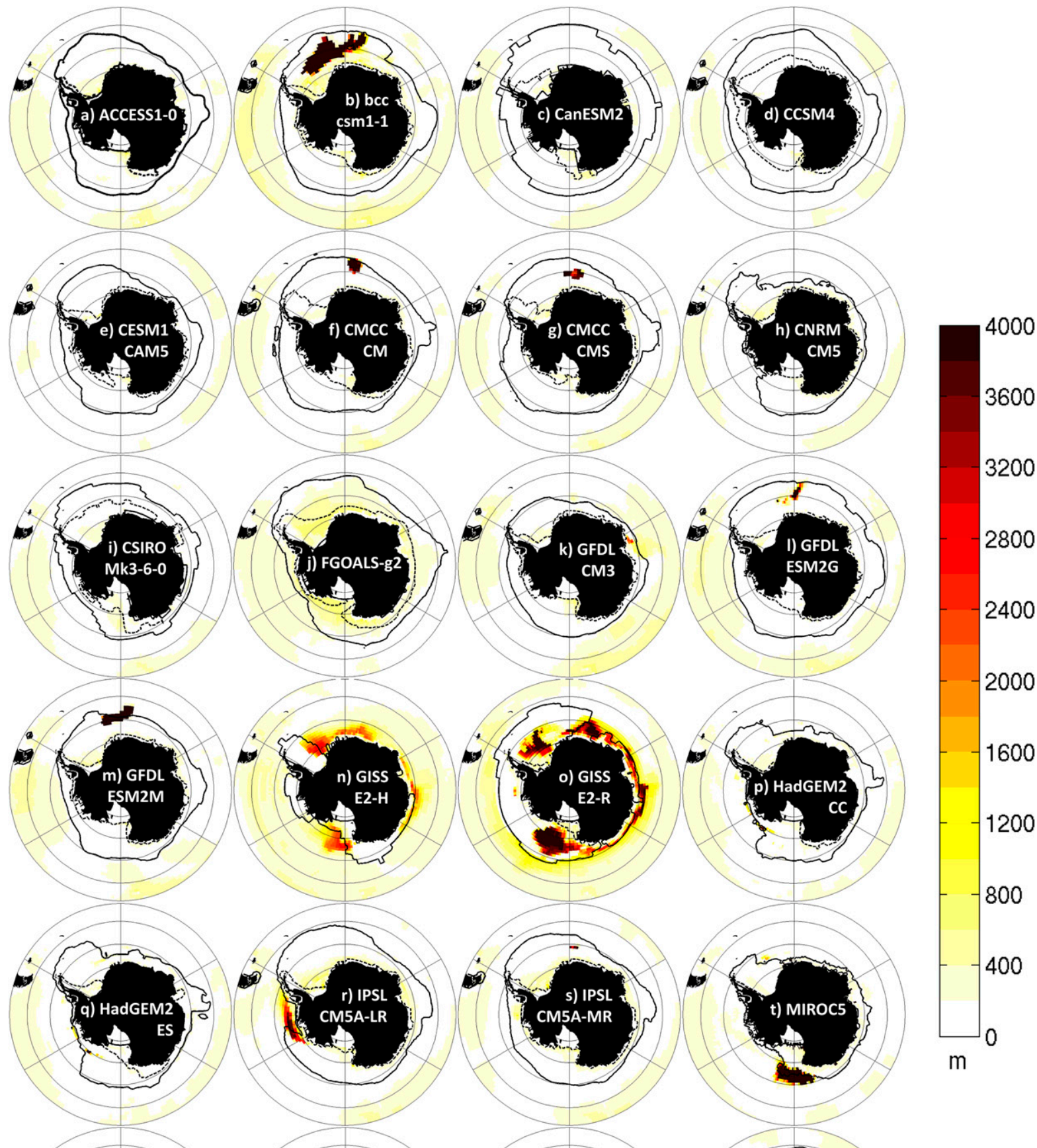

$\mathrm{m}$
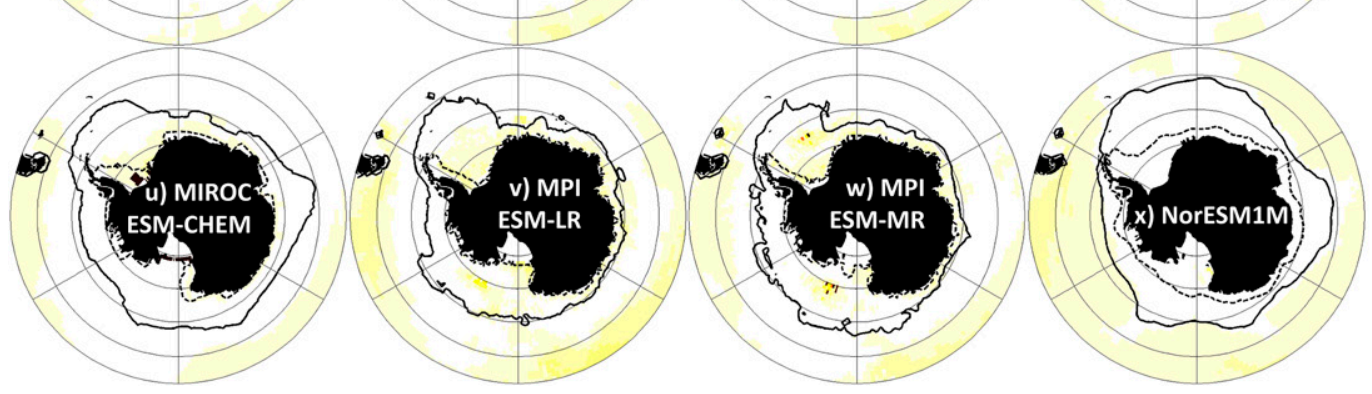

FIG. 4. As in Fig. 3, but for RCP8.5 (2081-2100). 


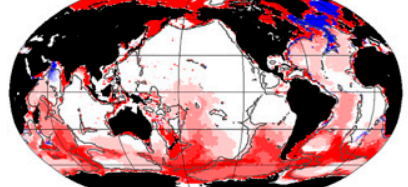

a) ACCESS1-0

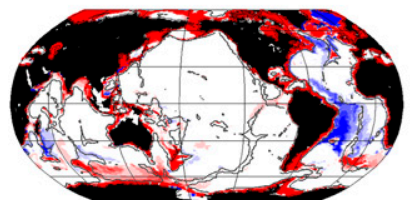

e) CESM1-CAM5

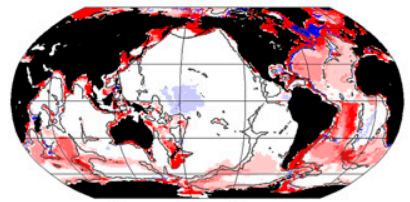

i) CSIRO-Mk3-6-0

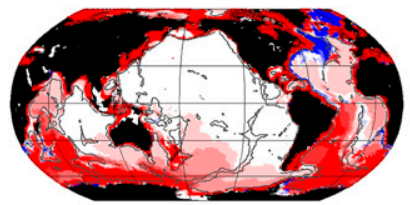

m) GFDL-ESM2M

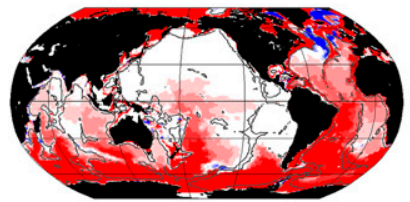

q) HadGEM2-ES

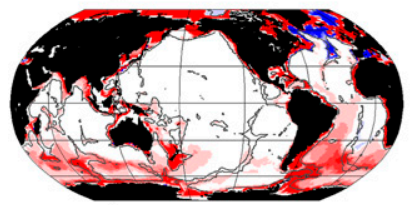

u) MIROC-ESM-CHEM

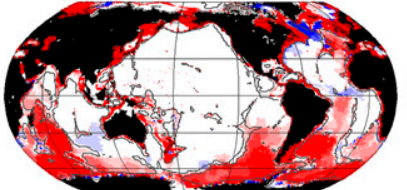

b) bcc-cms1-1

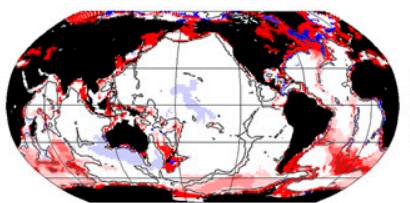

f) CMCC-CM

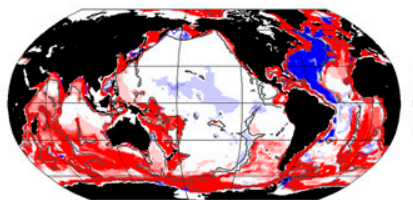

j) FGOALS-g2

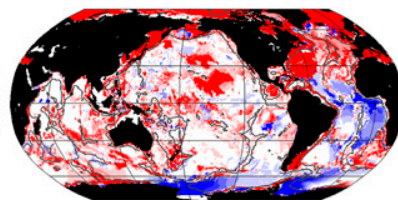

n) GISS-E2-H

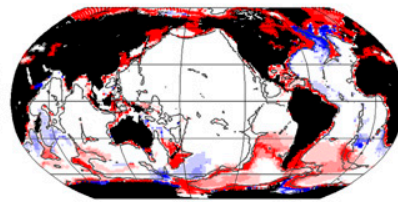

r) IPSL-CM5A-LR

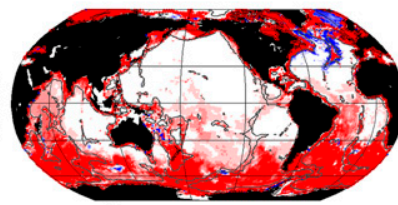

v) MPI-ESM-LR

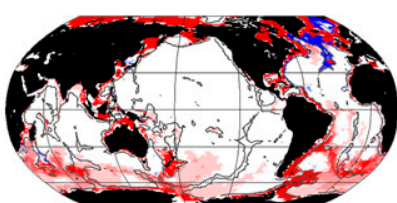

c) CanESM2

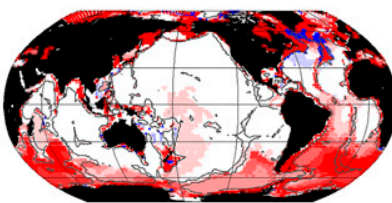

g) CMCC-CMS

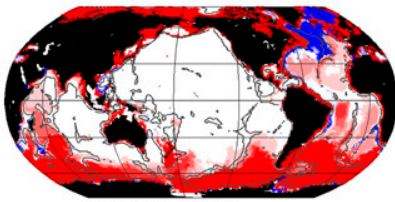

k) GFDL-CM3

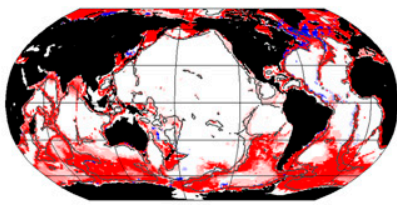

o) GISS-E2-R

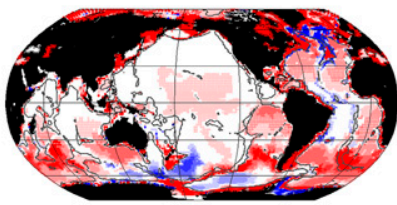

s) IPSL-CM5A-MR

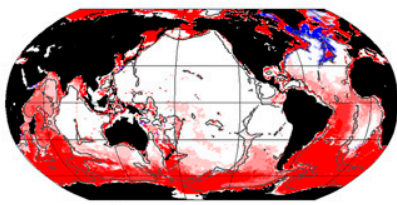

w) MPI-ESM-MR

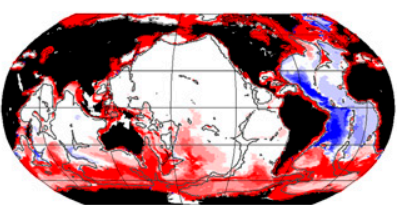

d) $\operatorname{CCSM} 4$

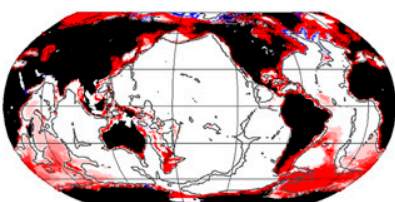

h) CNRM-CM5

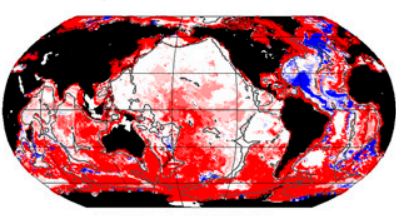

I) GFDL-ESM2G

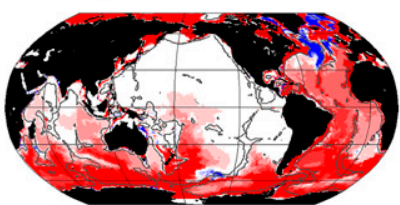

p) HadGEM2-CC

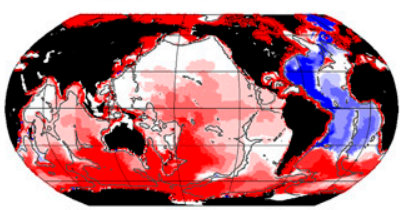

t) MIROC5

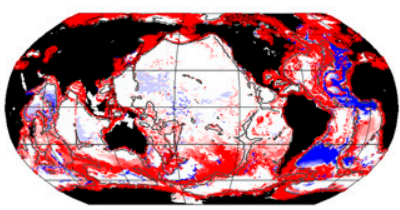

x) NorESM1-M

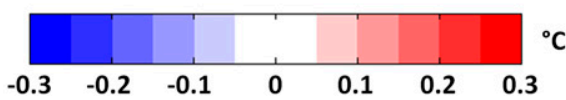

FIG. 5. RCP8.5 bottom temperature change (2081-2100 minus 1986-2005) for each model, with the same scale for all 24 models. Control drift has been removed. The dark gray contour indicates the $3000-\mathrm{m}$ isobath.

freshening $\left(0.004 \pm 0.004 \mathrm{~kg} \mathrm{~m}^{-3}\right)$. Interestingly, the model agreement is the strongest for density thanks to the combination of changes in both temperature and salinity. Because the density changes are mostly dominated by the temperature change, all 24 models become lighter in most of the Southern Hemisphere.

RCP4.5 exhibits the same patterns as RCP8.5 but with a smaller magnitude (not shown). The multimodel mean for RCP4.5 shows a warming of the bottom layer of the whole Southern Hemisphere of $0.08^{\circ} \pm 0.07^{\circ} \mathrm{C}$ and a cooling of the North Atlantic of $0.12^{\circ} \pm 0.11^{\circ} \mathrm{C}$. This results in the whole Southern Hemisphere becoming less dense by $0.006 \pm 0.004 \mathrm{~kg} \mathrm{~m}^{-3}$ at the bottom in RCP4.5. Overall, the changes in RCP 8.5 are enhanced by $40 \%$ compared with the changes in RCP4.5. Hereafter, the results and discussion refer to RCP8.5 only.

We now focus on the changes in bottom properties in the three deep oceans: the Pacific, Indian, and Atlantic (boundaries shown in Fig. 1c; see supplementary Tables S1-S3 for details of the changes in each latitude band). In the Pacific Ocean most models experience the strongest change in bottom density in the band $60^{\circ}-30^{\circ} \mathrm{S}$. 


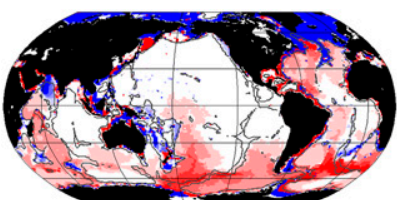

a) ACCESS1-0

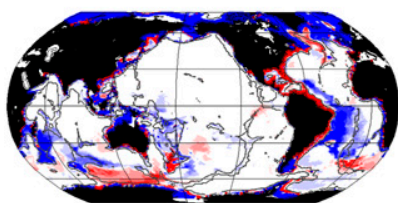

e) CESM1-CAM5

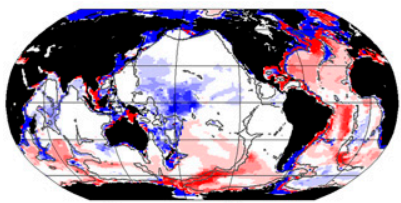

i) CSIRO-Mk3-6-0

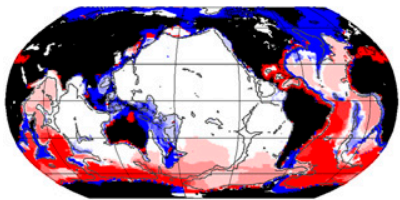

m) GFDL-ESM2M

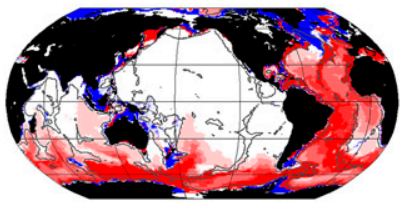

q) HadGEM2-ES

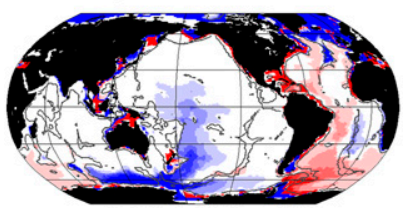

u) MIROC-ESM-CHEM

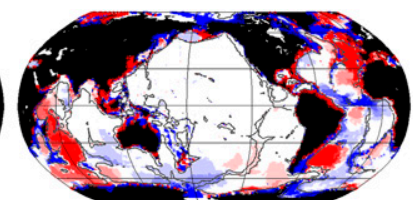

b) bcc-cms1-1

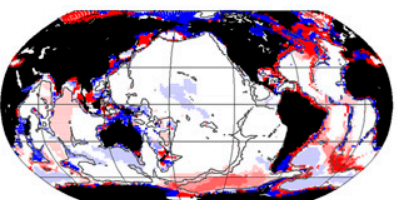

f) CMCC-CM

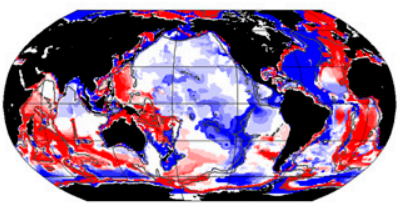

j) FGOALS-g2

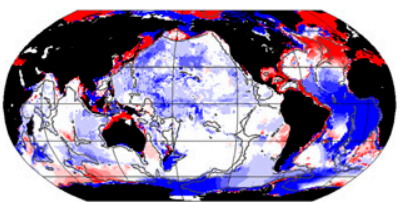

n) GISS-E2-H

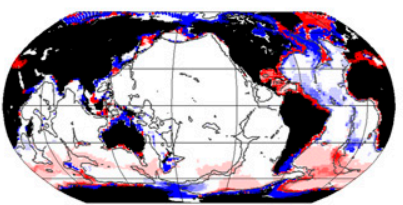

r) IPSL-CM5A-LR

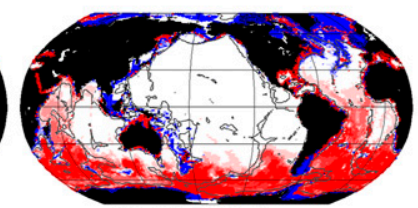

v) MPI-ESM-LR

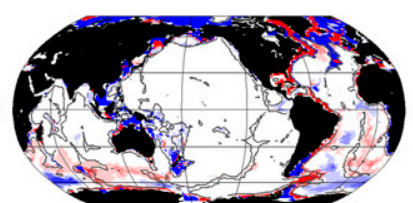

c) CanESM2

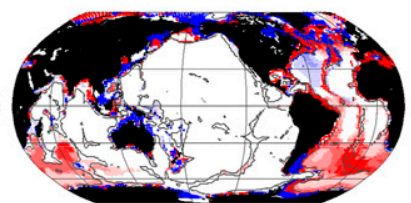

g) CMCC-CMS

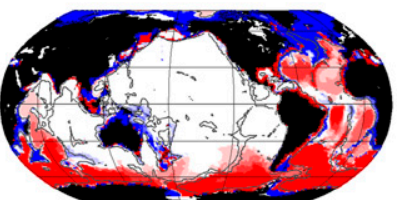

k) GFDL-CM3

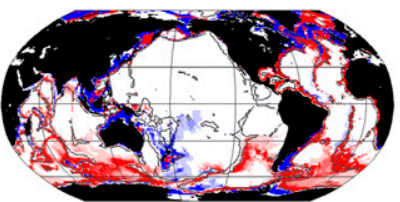

o) GISS-E2-R

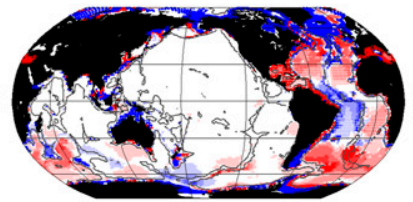

s) IPSL-CM5A-MR

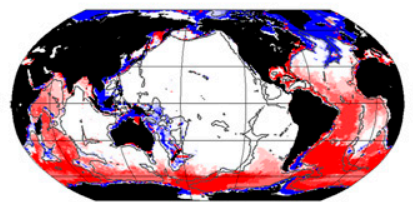

w) MPI-ESM-MR

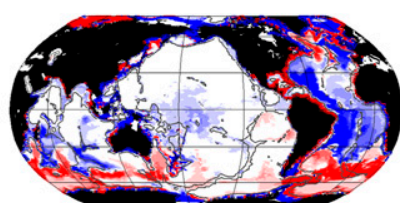

d) CCSM4

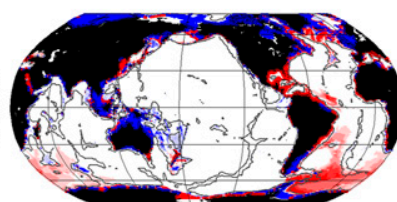

h) CNRM-CM5

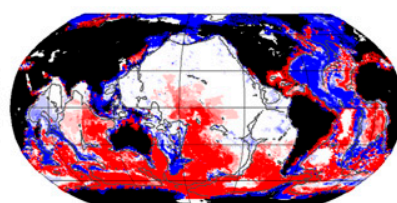

I) GFDL-ESM2G

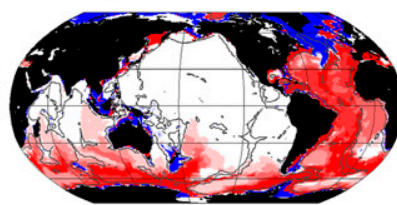

p) HadGEM2-CC

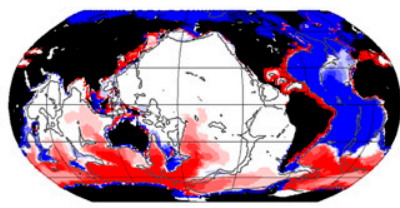

t) MIROC5

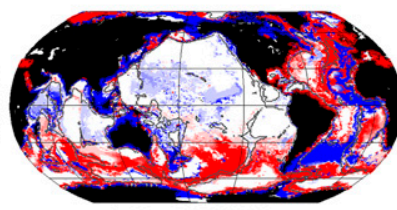

x) NorESM1-M

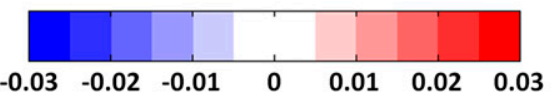

FIG. 6. As in Fig. 5, but for salinity.

In contrast, MIROC-ESM-CHEM has its strongest decrease in density between $80^{\circ}$ and $60^{\circ} \mathrm{S}$ because of its strong freshening in the Ross Sea $(-0.032)$. For CMCC-CM, GFDL-ESM2G, and MPI-ESM-MR, the strongest changes occur between $30^{\circ} \mathrm{S}$ and $0^{\circ}$ : farther south in the Pacific Ocean they exhibit an increase in salinity (up to 0.057 in the Ross Sea), which acts against the warming in changing the density. For most models, the magnitude of the change decreases northward.

In the deep Indian Ocean (deeper than $3000 \mathrm{~m}$ ), the strongest mean changes are found in the Northern Hemisphere. In fact, in the Southern Hemisphere all models exhibit a strong difference between the western and eastern Indian Ocean basins (Fig. 7): they become lighter west of the mid-Indian ridge but hardly have any change east of it. So, on average, changes in bottom density in the whole southern Indian Ocean appear weaker than in the Northern Hemisphere basin.

The deep Atlantic Ocean exhibits two peaks in bottom property changes: in the south between $60^{\circ}$ and $30^{\circ} \mathrm{S}$ and in the north between $30^{\circ}$ and $60^{\circ} \mathrm{N}$. In the Southern Hemisphere, the magnitude of the change decreases northward. The tropical Atlantic shows a decrease in density for all models (except INM-CM4). All models 


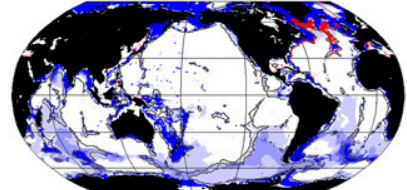

a) ACCESS1-0

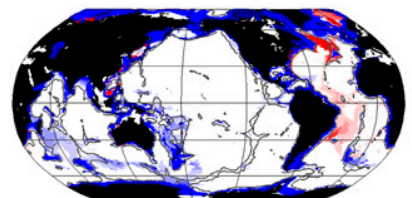

e) CESM1-CAM5

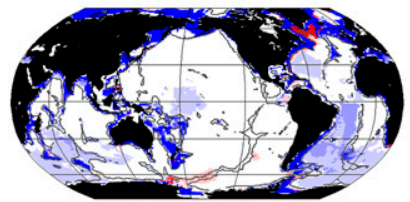

i) CSIRO-Mk3-6-0

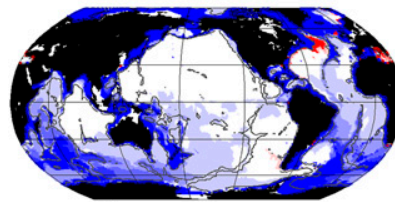

m) GFDL-ESM2M

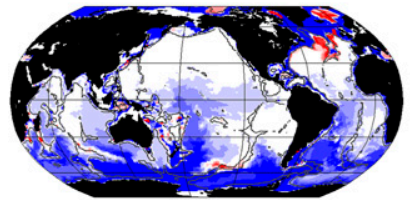

q) HadGEM2-ES

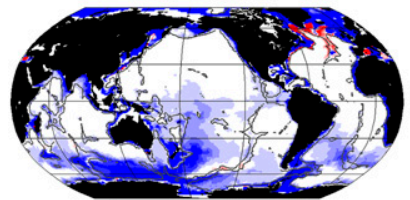

u) MIROC-ESM-CHEM

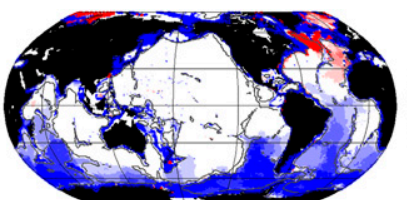

b) bcc-cms1-1

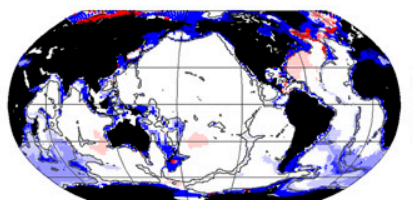

f) CMCC-CM

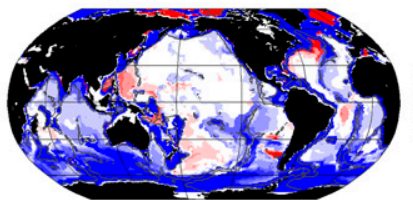

j) FGOALS-g2

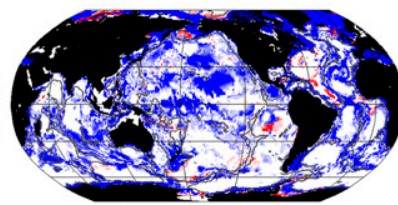

n) GISS-E2-H

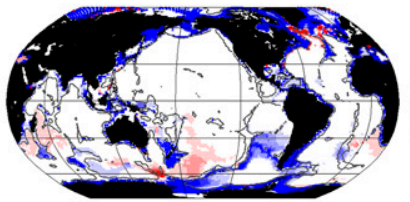

r) IPSL-CM5A-LR

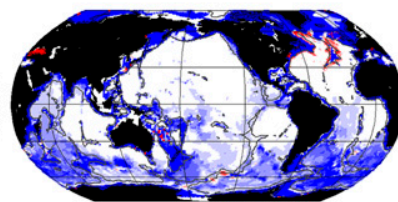

v) MPI-ESM-LR

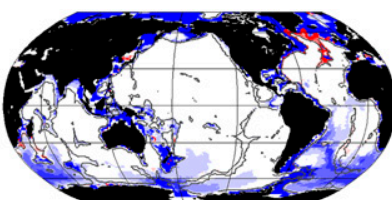

c) CanESM2

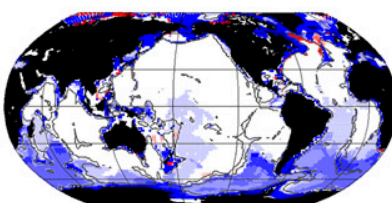

g) CMCC-CMS

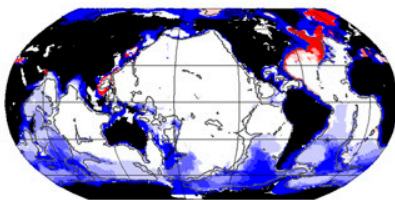

k) GFDL-CM3

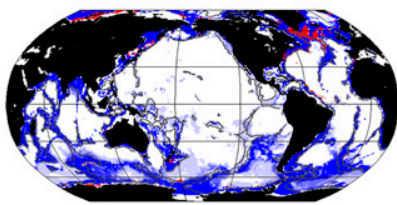

o) GISS-E2-R

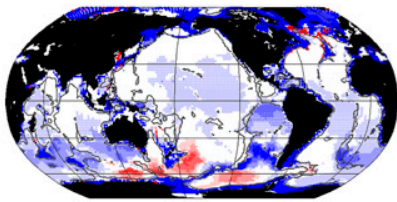

s) IPSL-CM5A-MR

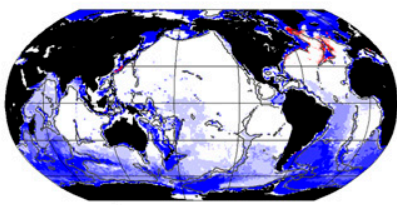

w) MPI-ESM-MR

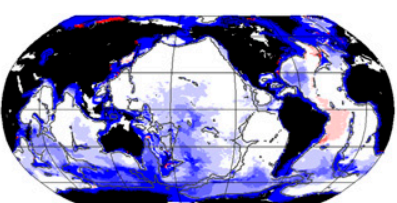

d) CCSM4

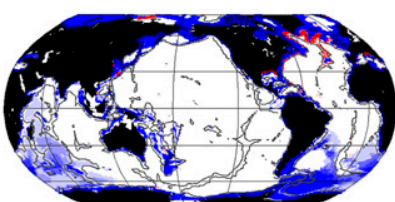

h) CNRM-CM5

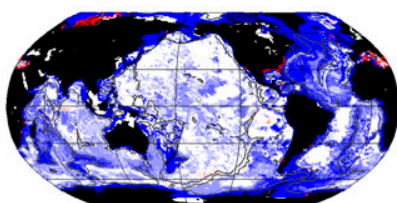

I) GFDL-ESM2G

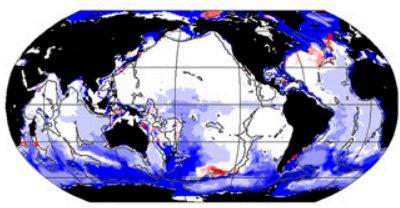

p) HadGEM2-CC

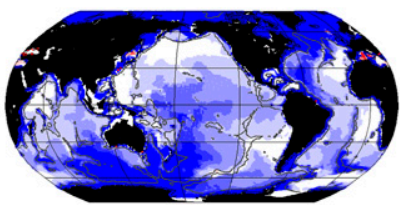

t) MIROC5

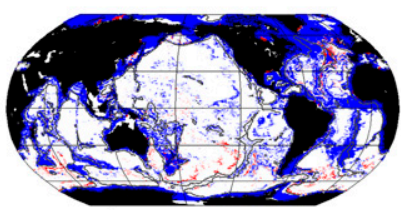

x) NorESM1-M

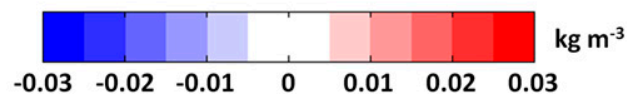

FIG. 7. As in Fig. 5, but for density.

have an increase in bottom density in some part of the North Atlantic (Fig. 7). As the area of increased density is relatively small in each model, the mean bottom density of the Atlantic from $30^{\circ}$ to $60^{\circ} \mathrm{N}$ decreases. The localized increase in bottom density associated with a cooling in the North Atlantic will be further discussed in section $3 \mathrm{~d}$.

\section{b. Mean volume transports: $A M O C, A C C$, and SMOCs}

In this section, we assess the mean values (Table 2) and dedrifted 1986-2100 time series (Fig. 8) of the main components of the deep and bottom water transports worldwide (we are not considering the eddy-induced component of these transports). In agreement with the 10 models presented by Cheng et al. (2013), we find that all models have a mean 1986-2005 AMOC calculated at $30^{\circ} \mathrm{N}$ between 10 and $25 \mathrm{~Sv}\left(1 \mathrm{~Sv} \equiv 10^{6} \mathrm{~m}^{3} \mathrm{~s}^{-1}\right)$, except for NorESM1-M, which is around $32 \mathrm{~Sv}$ (Table 2). Most models are within the range of the observed AMOC at $26.5^{\circ} \mathrm{N}$ of $17.4 \pm 4.8 \mathrm{~Sv}$ (Srokosz et al. 2012) and have improved since CMIP3 (Cheng et al. 2013). For all but one model the AMOC then weakens during the twentyfirst century (Fig. 8a). GISS-E2-H (light green dashed 

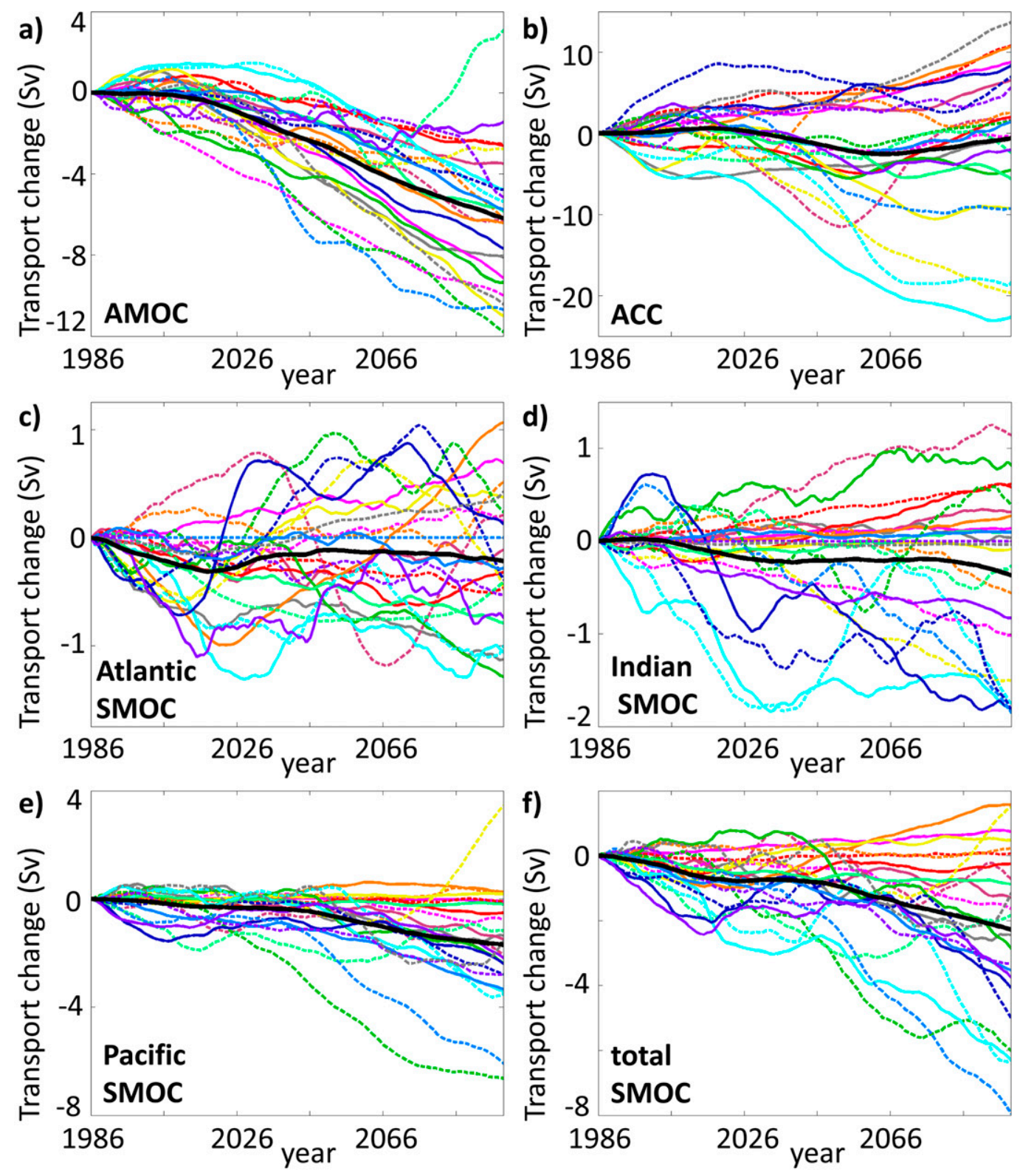

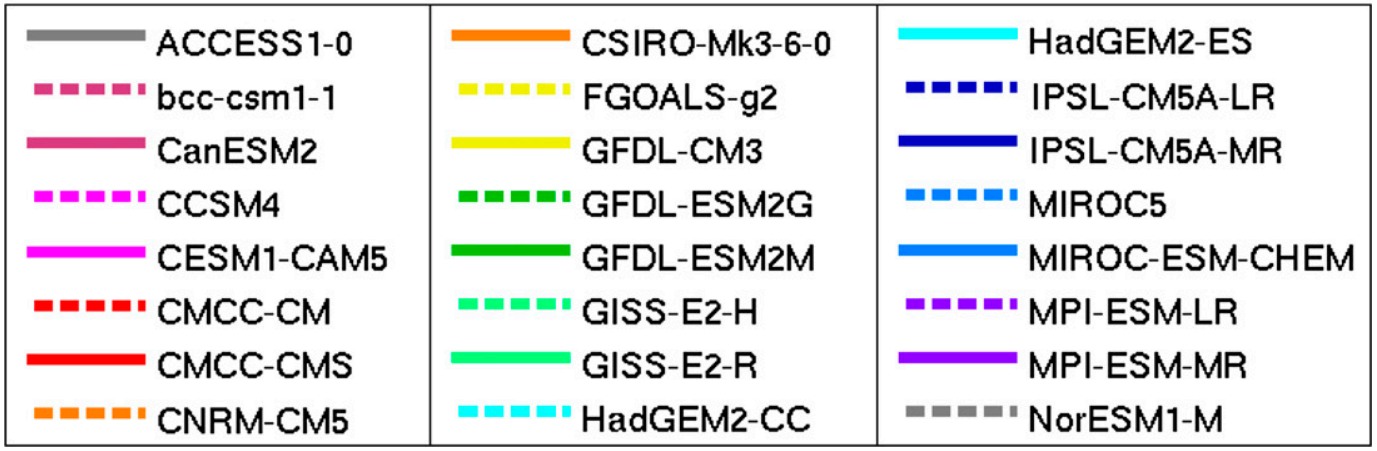

FIG. 8. RCP8.5 time series of the change in transport from the 1986 value for each model after removal of the control drift and 15-yr low-pass filtering: (a) Atlantic meridional overturning circulation at $30^{\circ} \mathrm{N}$, (b) Antarctic Circumpolar Current strength, (c) Atlantic bottom SMOC at $30^{\circ} \mathrm{S}$, (d) Indian SMOC, (e) Pacific SMOC, and (f) sum of the SMOCs (total SMOC). For each panel, the black line indicates the multimodel mean change. 
line) seems to increase from 2066: this is not a recovery of the AMOC but rather due to a sudden variation in the preindustrial control run. Because of this spurious behavior, we do not consider GISS-E2-H in this section and section 3c. The weakening of the AMOC is stronger by $60 \%$ in RCP 8.5 than in RCP4.5 (Fig. 9a), which is in agreement with the results of Cheng et al. (2013).

The strength and location of the ACC, by changing the volumes and properties of ventilated waters, impact both the properties and the meridional overturning circulation of the Southern Ocean (Dufour et al. 2012). The historical (1986-2005) mean ACC volume transport for each model for RCP8.5 is in agreement with the results of Meijers et al. (2012): most models have an ACC between 100 and $200 \mathrm{~Sv}$, except CNRM-CM5, which is a low outlier around $80 \mathrm{~Sv}$, while GISS-E2-R, MIROC5, and INM-CM4 are high outliers (Table 2). For all models, the interannual variability is below $20 \mathrm{~Sv}$ (Table 2). Models have improved their ACC representation since CMIP3 (Meijers et al. 2012), and so most agree with the observations of $134-164 \mathrm{~Sv}$ for the transport through Drake Passage (Griesel et al. 2012). Changes in ACC transport throughout the twenty-first century are relatively weak for most models (Fig. 8b): all but three models change by less than $10 \mathrm{~Sv}$ (i.e., less than $10 \%$ of their historical value) by 2100 . Only INM-CM4 exhibits a clear increase $(+45 \mathrm{~Sv}$ by 2100$)$ while we observe a substantial decrease only in HadGEM2-ES $(-25 \mathrm{~Sv})$ and HadGEM2-CC (about $-20 \mathrm{~Sv}$ ). The ACC in most models is insensitive to the choice of forcing (Fig. 9b). The causes for this insensitivity remain unclear (Meijers 2014): no consistency can be found among CMIP5 models, and there is no clear modeled dynamical link between the subpolar gyres and the ACC and no clear influence of the wind. Because of the influence of the eddy-induced transport on the ACC (Downes and Hogg 2013), it is key that modeling centers archive the Bolus velocities or transports for future CMIPs.

The SMOCs differ between the three ocean basins and will be discussed separately. In the Atlantic, most models export on average less than $6 \mathrm{~Sv}$ of bottom water northward in the historical run (Table 2), in agreement with box inverse model estimates by Sloyan and Rintoul (2001) and Lumpkin and Speer (2007) (about 3 Sv and $5.6 \pm 3 \mathrm{~Sv}$, respectively). INM-CM4 and MIROC5 have a mean northward transport of $0 \mathrm{~Sv}$, and GISS-E2-H and NorESM1-M have a very weak transport of less than $1 \mathrm{~Sv}$. For RCP8.5 by the end of the twenty-first century, 13 models have a weakened SMOC while 9 have a stronger SMOC (Fig. 8c). Apart from ACCESS1.0 (plain gray line), GFDL-ESM2M (plain green line), HadGEM2-CC (dashed cyan line), and HadGEM2-ES (plain cyan line), the change in volume transport is within the interannual variability of the models and hence not significant. Figure 9c shows that half of the models have a stronger change in RCP4.5 and the other half have a stronger change in RCP8.5, but for all models this difference is within the interannual variability range: hence the change between the two forcings is not significant.

The mean 1986-2005 volume transport of bottom water into the Indian Ocean is quite small (Table 2): for half of the models the Indian SMOC is less than $1 \mathrm{~Sv}$ (0 Sv for INM-CM4 and MPI-ESM-LR), while for the other models it is between 1 and $6 \mathrm{~Sv}$, as in the Atlantic. These results lie within the large range of observational values for the Indian SMOC (3-27 Sv) or model outputs (0-17 Sv), summarized by Huussen et al. (2012). Less than half of the models exhibit changes in their Indian SMOC stronger than the interannual variability (Fig. 8d): BCC_CSM1.1(m) and GFDL-ESM2-M increase throughout the twenty-first century, whereas the Indian SMOC decreases for FGOALS-g2, HadGEM2-CC, HadGEM2ES, IPSL-CM5A-LR, IPSL-CM5A-MR, and MIROC5. For all models but MPI-ESM-MR, the magnitude of the change is higher for RCP8.5 than for RCP4.5 (by $60 \%$ on average; Fig. 9d).

The Pacific SMOC 1986-2005 mean is higher than the Atlantic and Indian SMOCs (Table 2), and it is still the highest after normalizing by the width of the ocean basins at $30^{\circ} \mathrm{S}$ (not shown). Most models are between 1 and $11 \mathrm{~Sv}$, with the exception of GFDL-ESM2G, which is as high as $17 \mathrm{~Sv}$. Again, models lie within the range of the box inverse estimates of $11 \pm 5.1 \mathrm{~Sv}$ by Lumpkin and Speer (2007). Most models exhibit a change in Pacific SMOC during the twenty-first century above their interannual variability; apart from FGOALS-g2, which becomes stronger, the Pacific SMOC weakens by the end of the twenty-first century (Fig. 8e). For all models but IPSL-CM5A-MR and MPI-ESM-MR, the magnitude of the change is higher for RCP8.5 than for RCP4.5 (by $20 \%$ on average; Fig. 9e). Similar results are observed for the total SMOC (sum of the three SMOCs), as the Pacific SMOC dominates it; it weakens significantly for most models (Fig. 8f) and, for all models but IPSLCM5A-MR and MPI-ESM-MR, the weakening is stronger for RCP8.5 than for RCP4.5 (Fig. 9f).

In the following section, we study the links between each volume transport and bottom property changes. Beforehand, we need to investigate whether there are dynamical links among the transports for each model or if the transports can be considered relatively independent. Correlations were calculated between the RCP8.5 twenty-first-century AMOC, ACC, and SMOC time series for each model (supplementary Table S4). The nine models whose AMOC and ACC are both 

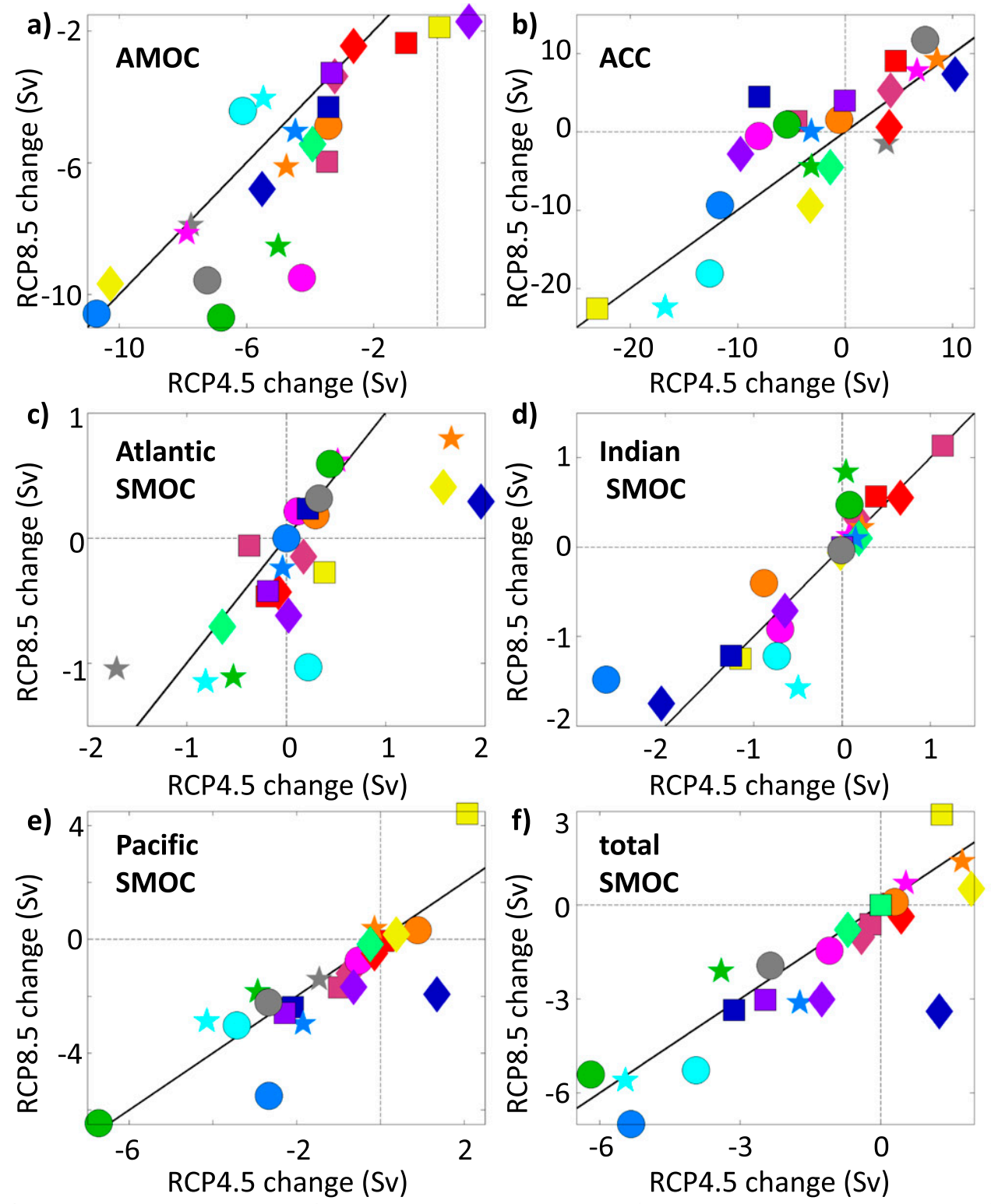

\begin{tabular}{|c|c|c|c|c|c|}
\hline $\begin{array}{l}\star \\
\square \\
\bullet \\
0 \\
\star \\
\square \\
\bullet \\
0\end{array}$ & $\begin{array}{l}\text { ACCESS1-0 } \\
\text { bcc-csm1-1 } \\
\text { CanESM2 } \\
\text { CCSM4 } \\
\text { CESM1-CAM5 } \\
\text { CMCC-CM } \\
\text { CMCC-CMS } \\
\text { CNRM-CM5 }\end{array}$ & $\begin{array}{l}\star \\
\square \\
\\
0 \\
\star \\
\bullet \\
0\end{array}$ & $\begin{array}{l}\text { CSIRO-Mk3-6-0 } \\
\text { FGOALS-g2 } \\
\text { GFDL-CM3 } \\
\text { GFDL-ESM2G } \\
\text { GFDL-ESM2M } \\
\text { GISS-E2-R } \\
\text { HadGEM2-CC }\end{array}$ & $\begin{array}{l}\star \\
\square \\
\bullet \\
0 \\
\star \\
\square \\
\bullet \\
0\end{array}$ & $\begin{array}{l}\text { HadGEM2-ES } \\
\text { IPSL-CM5A-LR } \\
\text { IPSL-CM5A-MR } \\
\text { MIROC5 } \\
\text { MIROC-ESM-CHEM } \\
\text { MPI-ESM-LR } \\
\text { MPI-ESM-MR } \\
\text { NorESM1-M }\end{array}$ \\
\hline
\end{tabular}

FIG. 9. Relationship between the change (2081-2100 minus 1986-2005) in each transport between RCP4.5 and RCP8.5: (a) AMOC, (b) ACC, (c) Atlantic SMOC, (d) Indian SMOC, (e) Pacific SMOC, and (f) total SMOC. Control drift has been removed. For all the panels, the black diagonal line is the $y=x$ line. 
TABLE 3. Pacific Ocean, correlations between the parameters ( $\sigma$ is potential density, $\theta$ is potential temperature, and $S$ is salinity) for each latitude band and the transports: mean 1986-2005 historical value ("historical"); mean 2081-2100 RCP8.5 value ("RCP8.5"); and difference of historical, RCP8.5, preindustrial control drift ("change"). Empty values indicate that no significant correlation ( $p$ value $<$ 0.05 ) was found. The model INM-CM4 was not included in the analysis. GISS-E2-H was removed from the transport changes because of its spurious preindustrial run values.

\begin{tabular}{|c|c|c|c|c|c|c|c|c|c|c|}
\hline Lat & Parameter & $\begin{array}{c}\text { Historical } \\
\text { ACC }\end{array}$ & $\begin{array}{c}\mathrm{RCP} 8.5 \\
\mathrm{ACC}\end{array}$ & $\begin{array}{c}\text { Change } \\
\text { ACC }\end{array}$ & $\begin{array}{c}\text { Historical } \\
\text { Pacific } \\
\text { SMOC }\end{array}$ & $\begin{array}{c}\text { RCP8.5 } \\
\text { Pacific } \\
\text { SMOC }\end{array}$ & $\begin{array}{c}\text { Change } \\
\text { Pacific } \\
\text { SMOC }\end{array}$ & $\begin{array}{c}\text { Historical } \\
\text { total } \\
\text { SMOC }\end{array}$ & $\begin{array}{c}\text { RCP8.5 } \\
\text { total } \\
\text { SMOC }\end{array}$ & $\begin{array}{c}\text { Change } \\
\text { total } \\
\text { SMOC }\end{array}$ \\
\hline \multirow[t]{3}{*}{$80^{\circ}-60^{\circ} \mathrm{S}$} & $\sigma$ & -0.59 & -0.46 & 0.82 & -0.39 & -0.42 & - & -0.34 & - & - \\
\hline & $\theta$ & - & - & -0.69 & 0.36 & - & - & 0.49 & - & -0.48 \\
\hline & $S$ & - & - & - & - & - & -0.42 & - & - & -0.38 \\
\hline \multirow{3}{*}{$60^{\circ}-30^{\circ} \mathrm{S}$} & $\sigma$ & -0.65 & -0.59 & 0.62 & - & - & - & - & - & - \\
\hline & $\theta$ & - & - & -0.44 & 0.41 & - & -0.65 & 0.37 & - & -0.69 \\
\hline & $S$ & - & - & - & - & - & -0.70 & - & - & -0.65 \\
\hline \multirow{3}{*}{$30^{\circ} \mathrm{S}-0^{\circ}$} & $\sigma$ & - & - & - & - & -0.36 & - & - & - & - \\
\hline & $\theta$ & - & - & -0.39 & 0.61 & 0.69 & - & 0.48 & 0.53 & - \\
\hline & $S$ & - & - & - & 0.51 & 0.47 & - & 0.44 & 0.42 & - \\
\hline \multirow[t]{3}{*}{$0^{\circ}-30^{\circ} \mathrm{N}$} & $\sigma$ & -0.40 & -0.39 & - & -0.56 & - & 0.64 & -0.48 & - & 0.70 \\
\hline & $\theta$ & - & - & - & 0.41 & - & -0.75 & 0.37 & - & -0.81 \\
\hline & $S$ & - & - & - & - & - & -0.36 & - & - & -0.38 \\
\hline \multirow[t]{3}{*}{$30^{\circ}-60^{\circ} \mathrm{N}$} & $\sigma$ & - & - & - & - & - & - & - & - & -0.41 \\
\hline & $\theta$ & - & - & - & -0.41 & - & - & -0.45 & -0.44 & - \\
\hline & $S$ & - & - & - & -0.40 & -0.51 & - & -0.37 & -0.51 & - \\
\hline
\end{tabular}

weakening are positively and significantly correlated, whereas the seven models whose ACC is increasing have a negative correlation. The AMOC is also positively correlated to the total SMOC for all models but CESM1 (CAM5), CSIRO Mk3.6.0, and GFDL CM3: this result suggests that the AABW cell and the North Atlantic Deep Water (NADW) cell vary in phase in most models as was shown by Swingedouw et al. (2009). In these three models the AMOC is negatively correlated with the Atlantic SMOC, suggesting that they exhibit a bipolar ocean seesaw (Brix and Gerdes 2003). Finally, there is little correlation between the SMOCs of each basin, despite each basin being strongly and positively correlated to the total SMOC. In summary, for the following section, any correlation found with the total SMOC is likely due to a correlation with one of the basin SMOCs. The other transports are not consistently linked among models: significant correlations between the bottom property changes and two transports, for example, can be considered as two different results.

\section{c. Relationships between the changes in bottom properties and the transports}

In this section, we investigate the across-model relationships between the climate-induced changes in bottom properties and both the magnitudes and the changes of the transports. These relationships do not indicate which one is causing the other but are an indication of a mechanistic link between two phenomena. We hypothesize that the bottom property changes (Fig. 5-7) may be advected equatorward by the volume transports. Assuming that these volume transports are mainly density driven, we also check whether a change in bottom density induces a change in transport. Causalities will be explained in more detail in the discussion (section 4).

In the Pacific Ocean (Table 3), the changes in bottom properties are linked with the historical value of the Pacific SMOC and of the total SMOC. From $80^{\circ} \mathrm{S}$ to $30^{\circ} \mathrm{N}$, the main correlation is found between the change in bottom temperature and the mean 1986-2005 Pacific SMOC: the stronger the transport, the larger the warming. In turn, bottom property changes alter the volume transports. In the Southern Hemisphere, bottom density (temperature) changes are significantly correlated (anticorrelated) to changes in the ACC and the total SMOC: decreases in density or increases in temperature are associated with a weakening of the ACC and the total SMOC. This means that property changes at the ocean floor are indicative of changes higher in the water column that affect the ACC transport. In the Northern Hemisphere, bottom density (temperature) changes are correlated (anticorrelated) to changes in both the Pacific and the total SMOC, with larger decreases in density associated with a stronger weakening of the transports.

Similarly, in the Indian Ocean (Table 4), bottom temperature changes in the Southern Hemisphere are mostly linked to the 1986-2005 mean Indian Ocean and total SMOCs. In the band $80^{\circ}-60^{\circ} \mathrm{S}$, the stronger the Indian Ocean and total SMOCs, the larger the decrease in density and the warming of the bottom of the ocean. 
TABLE 4. As in Table 3, but for the Indian Ocean.

\begin{tabular}{|c|c|c|c|c|c|c|c|c|c|c|}
\hline Lat & Parameter & $\begin{array}{l}\text { Historical } \\
\text { ACC }\end{array}$ & $\begin{array}{c}\text { RCP } 8.5 \\
\text { ACC }\end{array}$ & $\begin{array}{c}\text { Change } \\
\text { ACC }\end{array}$ & $\begin{array}{l}\text { Historical } \\
\text { Indian } \\
\text { SMOC }\end{array}$ & $\begin{array}{l}\text { RCP8.5 } \\
\text { Indian } \\
\text { SMOC }\end{array}$ & $\begin{array}{l}\text { Change } \\
\text { Indian } \\
\text { SMOC }\end{array}$ & $\begin{array}{c}\text { Historical } \\
\text { total } \\
\text { SMOC }\end{array}$ & $\begin{array}{l}\text { RCP8.5 } \\
\text { total } \\
\text { SMOC }\end{array}$ & $\begin{array}{l}\text { Change } \\
\text { total } \\
\text { SMOC }\end{array}$ \\
\hline \multirow[t]{3}{*}{$80^{\circ}-60^{\circ} \mathrm{S}$} & $\sigma$ & -0.43 & - & 0.88 & -0.41 & - & 0.45 & -0.57 & -0.58 & 0.66 \\
\hline & $\theta$ & 0.42 & - & -0.77 & 0.40 & - & - & 0.53 & 0.45 & -0.61 \\
\hline & $S$ & - & - & - & - & - & - & - & - & - \\
\hline \multirow[t]{3}{*}{$60^{\circ}-30^{\circ} \mathrm{S}$} & $\sigma$ & -0.54 & -0.44 & 0.61 & - & - & - & - & - & 0.40 \\
\hline & $\theta$ & - & - & -0.65 & 0.41 & - & - & 0.49 & - & -0.49 \\
\hline & $S$ & - & - & -0.51 & - & - & - & - & - & -0.44 \\
\hline \multirow{3}{*}{$30^{\circ} \mathrm{S}-0^{\circ}$} & $\sigma$ & - & - & - & - & - & - & - & - & - \\
\hline & $\theta$ & - & - & -0.57 & - & - & - & 0.53 & 0.63 & -0.51 \\
\hline & $S$ & - & - & -0.59 & - & - & - & 0.43 & 0.56 & - \\
\hline \multirow[t]{3}{*}{$0^{\circ}-30^{\circ} \mathrm{N}$} & $\sigma$ & - & - & - & - & - & - & - & - & - \\
\hline & $\theta$ & - & - & - & - & - & - & - & - & - \\
\hline & $S$ & - & - & - & -0.54 & -0.54 & - & - & - & - \\
\hline
\end{tabular}

Between $60^{\circ}$ and $30^{\circ} \mathrm{S}$, the models with the strongest Indian Ocean and total SMOCs are the ones that become the warmest. In turn, bottom property changes are associated with changes in the ACC and in the total SMOC: there are significant negative correlations between the bottom temperature changes and the transport changes from $80^{\circ} \mathrm{S}$ to the equator and positive correlations with the bottom density changes from $80^{\circ}$ to $30^{\circ} \mathrm{S}$. For both transports, the larger the decrease in density or the increase in temperature, the weaker the transport becomes.

In the Atlantic Ocean (Table 5), changes in bottom property are associated with the 1986-2005 mean value of the total SMOC between $80^{\circ}$ and $60^{\circ} \mathrm{S}$, and with the historical value of the Atlantic SMOC up to $30^{\circ} \mathrm{N}$; models with a strong bottom water transport are the ones with strong warming and decrease in density. Between $30^{\circ}$ and $60^{\circ} \mathrm{N}$, changes in bottom property are primarily associated with the mean 2081-2100 value of the AMOC: the weaker the AMOC, the larger the warming and decrease in density. These changes are mostly due to a decrease of the North Atlantic deep convection and will be discussed in section $3 \mathrm{~d}$. Up to $30^{\circ} \mathrm{N}$, changes in bottom properties are correlated mostly with changes in the ACC, Atlantic and total SMOC. The warmer the model becomes, the larger the transport weakening. Changes in the AMOC are correlated with changes in salinity in the tropical Atlantic: the fresher the model, the weaker the AMOC. We will show in the next section that in fact, the weakening of the AMOC allows relatively fresh AABW to travel farther north.

\section{d. Deep convection in the North Atlantic}

In the North Atlantic, we found a cooling of the bottom layer in all models (Fig. 5) yet a weakening of the
AMOC. To see if the cooling may have come from the surface waters to the bottom by diffusion or mixing, we look at the change of properties throughout the whole water column in the Labrador sector of the North Atlantic (hashed region in Fig. 2b). Six (one) models exhibit a warming (cooling) through the whole water column (Fig. 10a). For most models and the multimodel mean, surface and intermediate waters are warmer at the end of the twenty-first century, whereas water at depth is colder (below $2600 \mathrm{~m}$ for the multimodel mean). Over the same area, four models freshen through the whole water column (Fig. 10b). For the other models, the sign of the salinity change varies with depth, although this variation is less systematic than it is in temperature. The multimodel mean is fresher below $2000 \mathrm{~m}$, but saltier between $200 \mathrm{~m}$ and $2000 \mathrm{~m}$. We observe a redistribution of heat which mainly indicates an increased stratification in these regions. To understand this phenomenon, we investigate the evolution of North Atlantic deep convection in RCP8.5 by studying the mixed layer depth (MLD) in models.

CMIP5 models and observations alike do not have deep MLD everywhere in the North Atlantic but rather at specific locations (Fig. 2b); hence, we divide the North Atlantic into three sectors (shown in Fig. 2b): the Labrador Sea and south of Greenland (LA), the Iceland and Irminger basins (II), and the Norwegian and Greenland Seas (NG). The maximum 1986-2005 MLD for the 24 CMIP5 models (Fig. 11) is deeper than $1000 \mathrm{~m}$ in the LA sector for all models (apart from INM-CM4; Fig. S4j). Eight models do not do deep convection in the II sector: CCSM4, CESM1 (CAM5), CNRM-CM5, HadGEM2-CC, HadGEM2-ES, MPI-ESM-LR, MPI-ESM-MR, and NorESM1-M (Figs. 11d,e,h,p,q,v,w,x, respectively). CNRM-CM5 does not convect deeply in the NG sector either: CMCC-CM does not either (Fig. 11e). All 


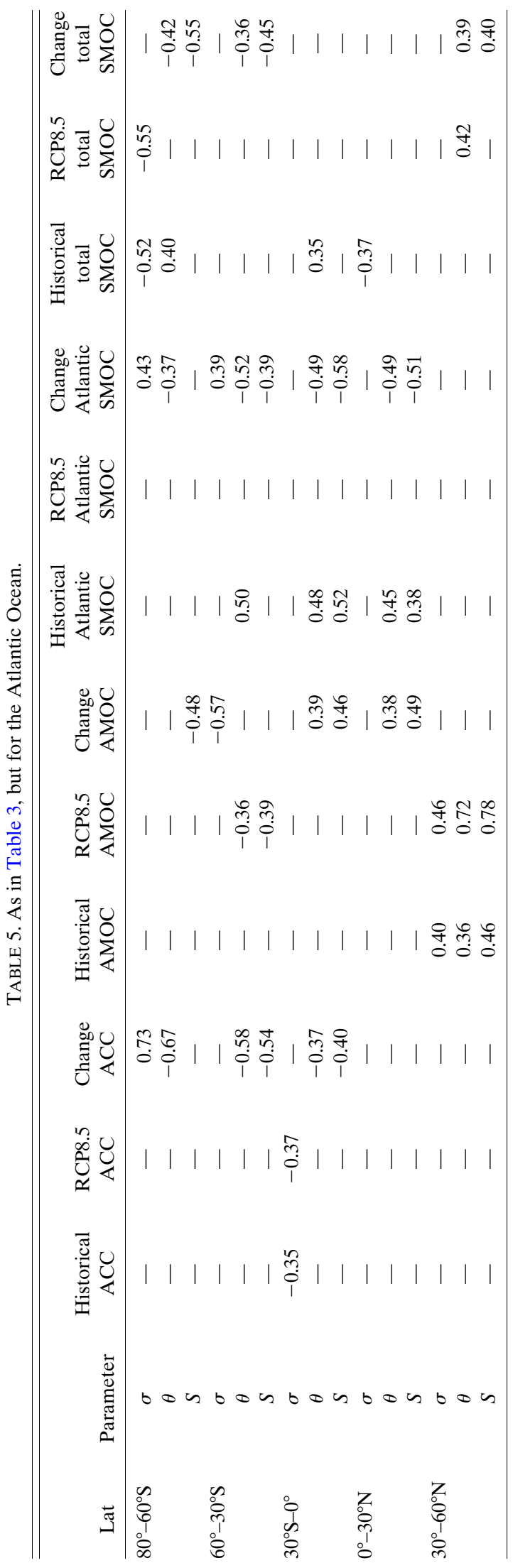

models have some deep convection in the North Atlantic during the period 1986-2005. Note that strong deep convection for MIROC5 and MIROC-ESM-CHEM in the North Sea regions (Figs. 11t,u) is an artefact of the models associated with an inaccurate representation of bathymetry and will not be discussed here: the North Sea is deeper than $4000 \mathrm{~m}$ in these models, whereas it is shallower than $1000 \mathrm{~m}$ in reality.

For RCP8.5, at the end of the twenty-first century (Fig. 12), most models have ceased any deep convection in the North Atlantic. Only BCC_CSM1.1 convects in all three sectors (Fig. 12b); GISS-E2-H and NorESM1-M still convect in both the LA and NG sectors, whereas ACCESS1.0, FGOALS-g2 and GISS-E2-R convect in the LA and II sectors (Figs. 12n, x,a,j,o, respectively). Finally, CanESM2 still has deep convection in the LA sector, and CSIRO Mk3.6.0, GFDL CM3, and GFDLESM2M only convect in the II sector (Figs. 12i,k,m). For these models, even if deep convection did not stop, its area has decreased on average by $70 \%$. Sea ice formation and its resulting brine rejection controls deep convection, yet we found no significant link between the decrease in deep convection and changes in sea ice. We can anyway note that all models but the two CMCC are ice free in the North Atlantic in summer by the end of the twenty-first century, and the winter ice cover has shrunk for all models (Fig. 12). Changes in deep convection area and changes in the AMOC are significantly correlated in the II sector only $(+0.36)$. We can hypothesize that changes in deep convection and in the AMOC have the same cause, surface waters freshening (Jahn and Holland 2013), although we did not find any significant relationship between the area of deep convection in any of the three sectors and the mean surface property changes that can be seen in Fig. 10.

There is a positive significant across-model correlation between the bottom property changes in the band $30^{\circ}-$ $60^{\circ} \mathrm{N}$ of the Atlantic and the area of deep convection by the end of the twenty-first century in the LA sector $(0.58$ for $\sigma_{2}, 0.49$ for the temperature, and 0.64 for the salinity) and in the NG sector ( 0.44 for the temperature and 0.47 for the salinity). That means that the models that have warmed and become saltier or the ones whose temperature and salinity have decreased the least are the models with stronger deep convection. Bottom density changes are also associated with changes in deep convection area in the II area (0.34). Temperature changes dominate the density changes in four models (CCSM4, CMCC-CMS, CSIRO Mk3.6.0, and HadGEM2-CC), and temperature and salinity changes both act toward a decrease in density for 14 other models. Only in BCC_CSM1.1, CanESM2, GISS-H, and NorESM1-M does the salinification compensate for a warming of the North Atlantic region. 

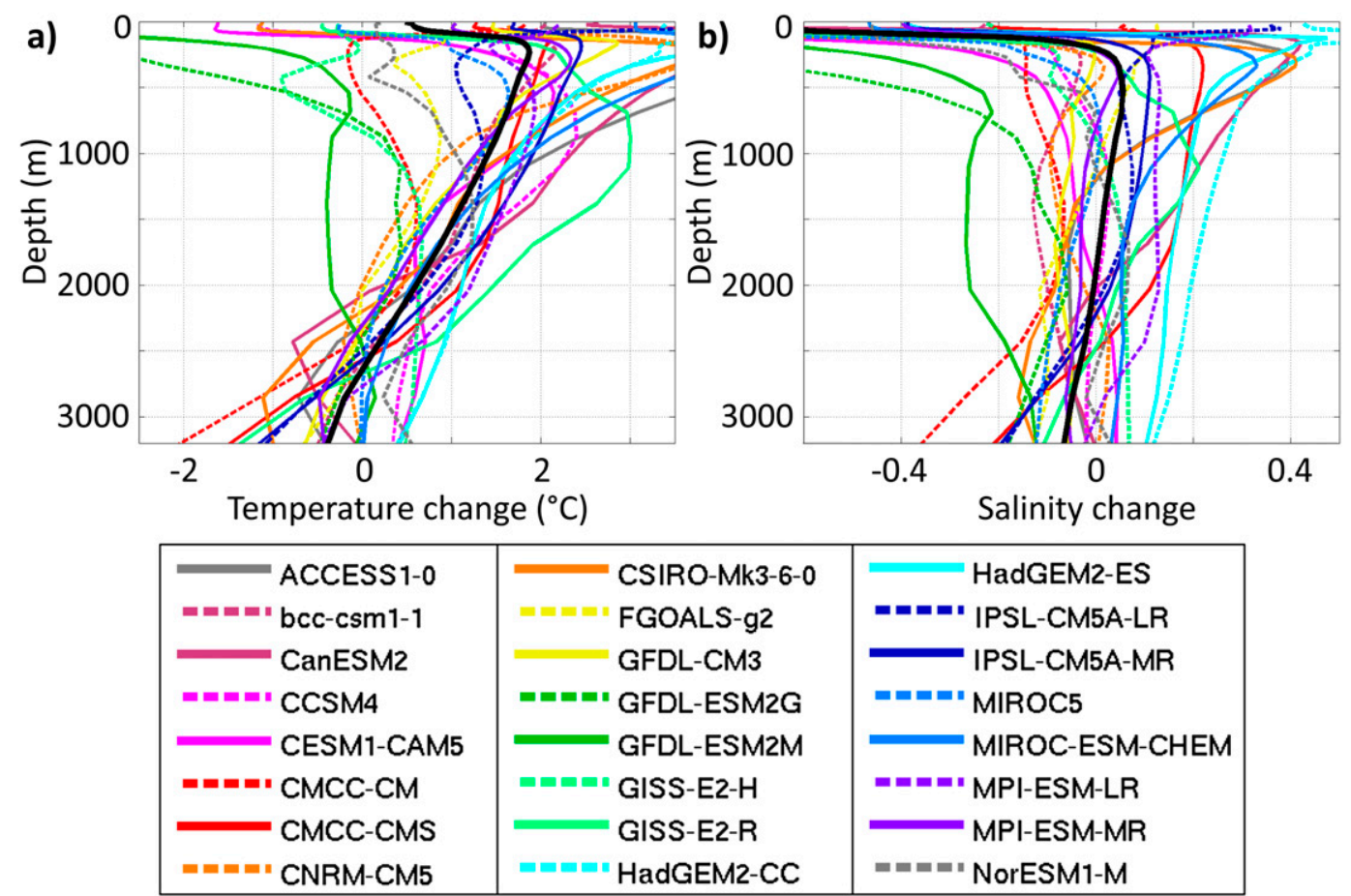

FIG. 10. RCP8.5, change (2081-2100 minus 1986-2005) in the profile of (a) temperature and (b) salinity for each model (colors) and the multimodel mean (black) in the Labrador Sea. For each model, the profile displayed is the mean of the profiles over the area of the North Atlantic shown in Fig. 2 for the grid cells whose bathymetry is between 3200 and $3500 \mathrm{~m}$.

However, these relationships do not explain how shallower mixing could bring a cooling to the bottom of the ocean. Maps of the actual mean value of the bottom density between 2081 and 2100 for RCP8.5 (Fig. 13) reveal that the cooling and freshening of North Atlantic bottom waters is due to the intrusion of a different, denser water mass. For all but one model, this water mass seems to have a southern origin: the bottom density in the Atlantic decreases northward. Only CSIRO Mk3.6.0 seems to form its densest water locally east of Greenland, probably by deep convection (Figs. 12i and 13i). For the other models, we suspect that the decrease of deep convection in the Nordic and Labrador Seas leads to less NADW formation. That leaves room for AABW to fill the bottom of the ocean farther north in the North Atlantic. The decrease in deep convection in the three sectors obviously does not locally cool the ocean, but it is the mechanism responsible for letting a colder water mass intrude into the deep North Atlantic.

\section{Discussion}

We now address the pathways through which bottom water properties and transports could be altered through climatic warming. We first hypothesize that the changes in bottom property have a southern origin for all basins but the North Atlantic. In the real ocean, the bottom water that fills the three deep basins originates from the Antarctic regions (Johnson 2008); in CMIP5 models, AABW is formed by open ocean deep convection in the Antarctic subpolar gyres (Heuzé et al. 2013). Open ocean deep convection is an effective way to modify the properties at the bottom of the ocean (Killworth 1983). In our study, 19 models have some open ocean deep convection in the last $20 \mathrm{yr}$ of the historical run (Fig. 3), and despite a large reduction in area only 4 of them have totally stopped deep convection in the Southern Ocean at the end of the twenty-first century (Fig. 4). In the Atlantic and Pacific Ocean, and less obviously in the Indian Ocean, changes in bottom water properties are the strongest south of $30^{\circ} \mathrm{S}$ and then decrease northward to $30^{\circ} \mathrm{N}\left(60^{\circ} \mathrm{N}\right.$ for the Pacific) as was observed at the bottom of the real oceans (Johnson et al. 2007). Bottom property changes in CMIP5 models first occur at the bottom of the Antarctic subpolar gyres following open ocean deep convection; hence, the strongest change signal is in the south. We can assume that bottom property changes will become less intense after 2100 as most CMIP5 models predict a shutdown of Southern Ocean deep convection during the twentysecond or twenty-third centuries (de Lavergne et al. 2014). 


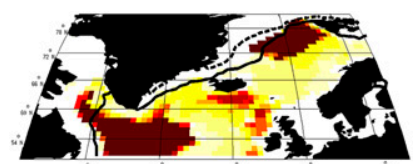

a) ACCESS1-0

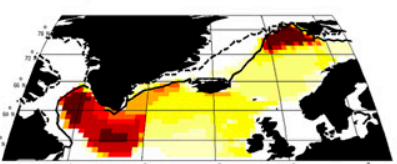

e) CESM1-CAM5

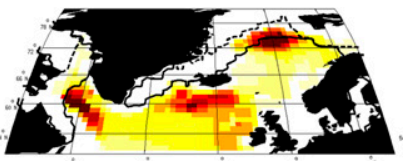

i) CSIRO-Mk3-6-0

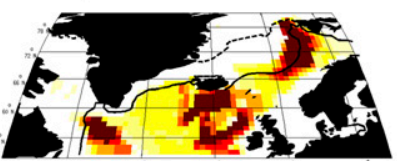

m) GFDL-ESM2M

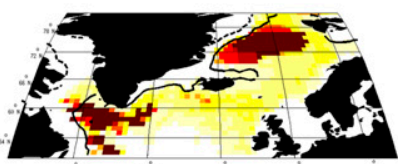

q) HadGeM2-ES

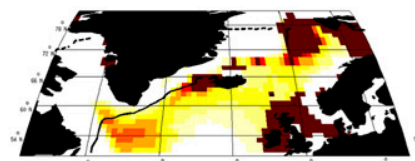

u) MIROC-ESM-CHEM

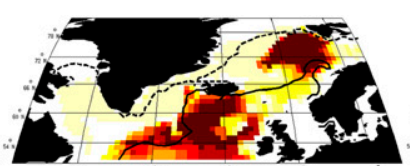

b) bcc-csm1-1

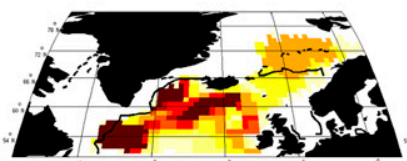

f) CMCC-CM

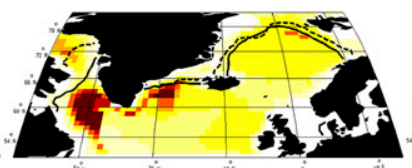

j) FGOALS-g2

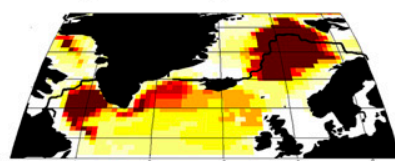

n) GISS-E2-H

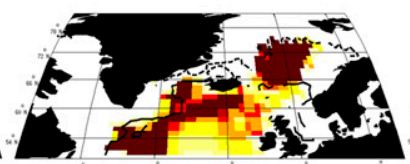

r) IPSL-CM5A-LR

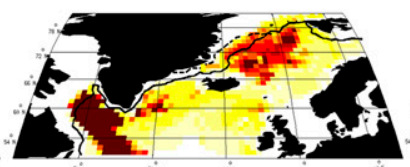

v) MPI-ESM-LR

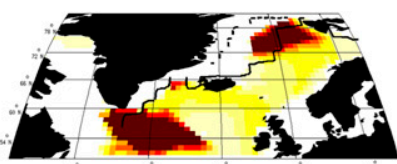

c) CanESM2

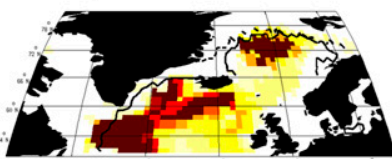

g) CMCC-CMS

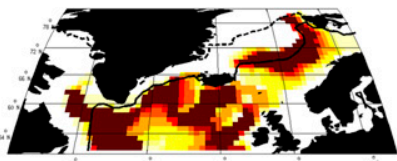

k) GFDL-CM3

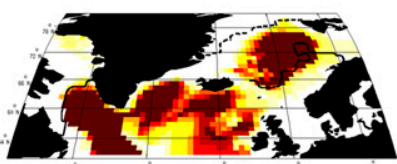

o) GISS-E2-R

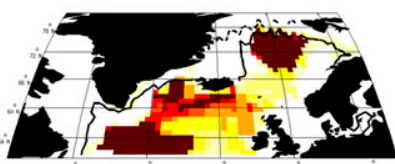

s) IPSL-CM5A-MR

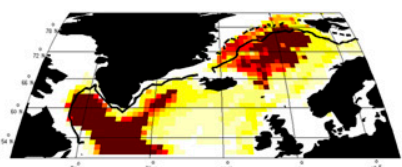

w) MPI-ESM-MR

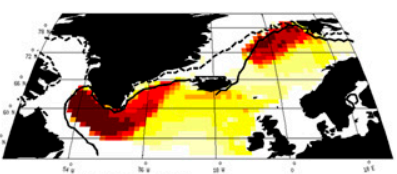

d) $\operatorname{CSSM} 4$

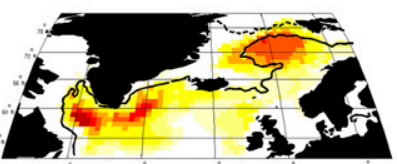

h) CNRM-CM 5

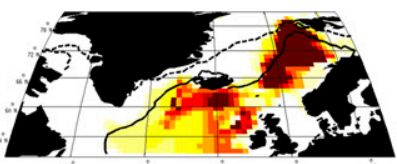

I) GFDL-ESM2G

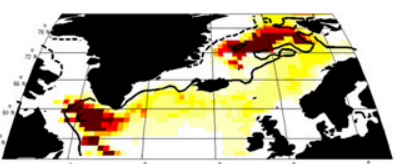

p) HadGEM2-CC

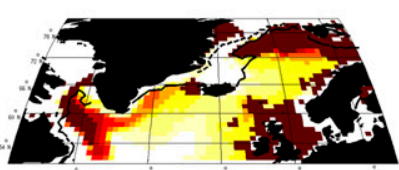

t) MIROC5

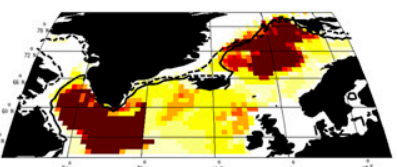

x) NorESM1-M

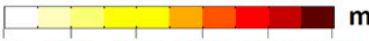

$0 \quad 400800120016002000$

FIG. 11. North Atlantic historical (1986-2005) maximum depth of the mixed layer in any month of the 20 years, for each model and each grid cell. Black lines indicate the mean March sea ice extent (plain line) and the mean September sea ice extent (dashed line).

Next, we consider how the bottom property changes propagate northward. We found strong significant correlations between bottom property changes and historical means of the transports in the three deep basins (Tables 3-5), which means that the stronger the volume transport at the start of the climate change run, the stronger the bottom property change $100 \mathrm{yr}$ later for each model. These correlations suggest that strong northward AABW transports lead to strong bottom water property changes. Could the changes come from the north and propagate southward? Global maps of these changes for each model (Figs. 5-7) make this unlikely, because the changes are stronger in the south and decrease northward. This could be confirmed by injecting tracers at both ends of each basin to precisely determine the circulation of deep and bottom waters. This is important as changes to the east-west gradient in properties will impact the meridional transport strength.

We found a good agreement between the 1986-2005 mean transports (Table 2) and the observations and box inverse estimates of these transports. However, we could not take into account the eddy-induced transport as too few CMIP5 models had made this output available. Because of the significant impact of the eddy component of the velocity on the ACC (Downes and Hogg 2013) and on decadal and longer time scales (Lee et al. 1997), there is an urgent need for climate modeling centers to provide this output.

The behavior in the North Atlantic is different from that of the Southern Hemisphere. In the real ocean, NADW is formed by deep convection in the Labrador, Greenland, Iceland, and Norwegian Seas (Johnson 2008); in CMIP5 models, we have seen that deep 


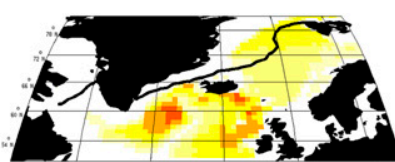

a) ACCESS1-0

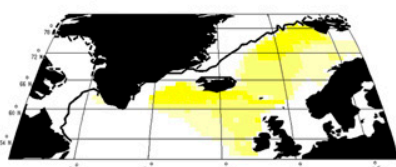

e) CESM1-CAM5

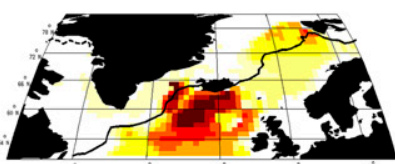

b) bcc-csm1-1

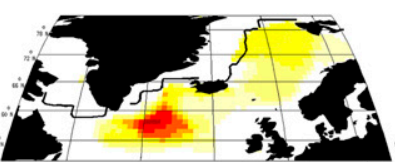

c) CanESM2

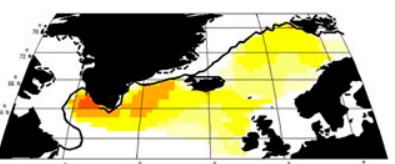

d) $\cos 4$

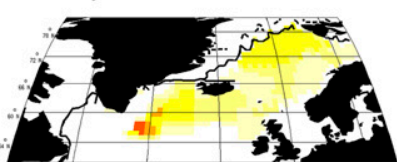

f) $\mathrm{CMCC}-\mathrm{CM}$

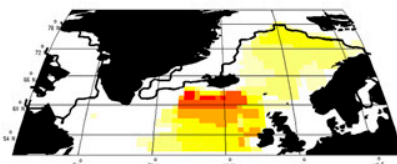

i) CSIRO-Mk3-6-0

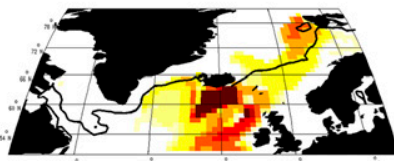

m) GFDL-ESM2M

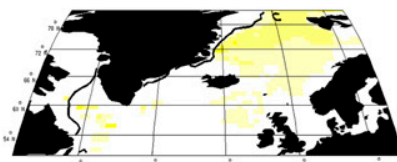

q) HadGEM2-ES

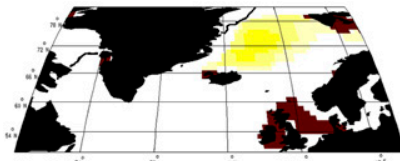

u) MIROC-ESM-CHEM

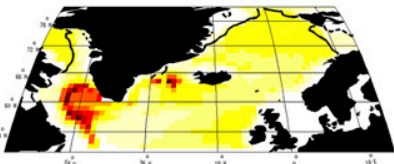

j) FGOALS-g2

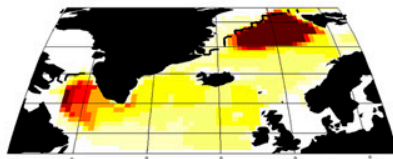

n) GISS-E2-H

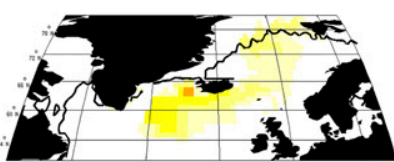

r) IPSLE-CM5A-LR

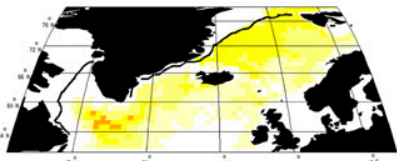

v) MPI-ESM-LR

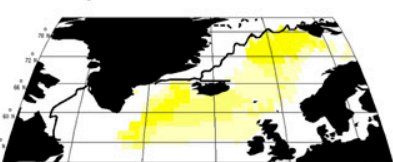

g) CMCC-CMS

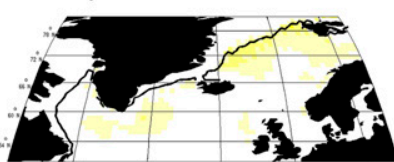

h) CNRM-CM5
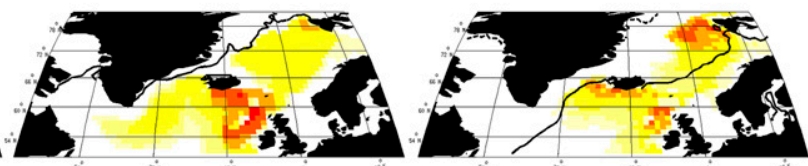

k) GFDL-CM3

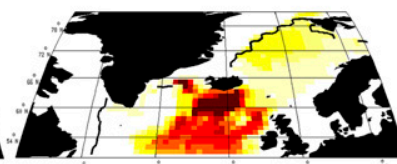

o) GISS-E2-R

I) GFDL-ESM2G

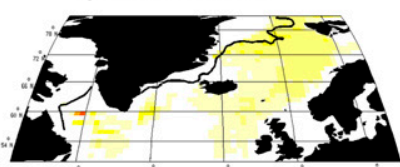

p) HadGEM2-CC

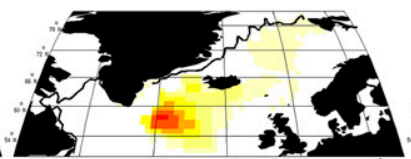

s) IPSLi-CM5A-MR

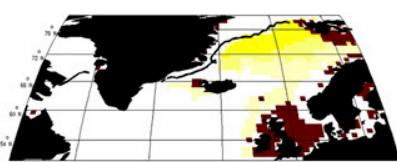

t) MIROC5

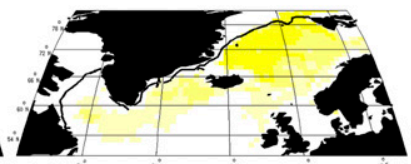

w) MPI-ESM-MR

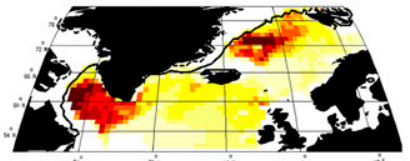

x) NorESM1-M

$0 \quad 400800120016002000$

FIG. 12. As in Fig. 11, but for RCP8.5 (2081-2100).

convection is significantly reduced or even stops during the twenty-first century (Fig. 12). Like Drijfhout et al. (2012), we found that deep convection decreases in the whole North Atlantic under a strong climate change scenario. All models experience a cooling (Fig. 5) and freshening (Fig. 6) locally in the North Atlantic, but these changes are limited to the deep ocean. The whole water column becomes more stratified (Fig. 10) with warming at middepth, a warming that may already be apparent in observations as shown by Levitus et al. (2000). Mignot et al. (2007) simulated the cessation of NADW formation and showed that waters from the south would enter the North Atlantic basin at intermediate depths. We found that a decrease in NADW formation allows more modified AABW, which is colder and fresher than NADW, to enter the North Atlantic from the tropical Atlantic (Fig. 13). This phenomenon has been observed in paleo records: during Heinrich events (large glacier discharge), North Atlantic Deep Water formation stopped and the bottom of the North Atlantic filled with waters from the Southern Ocean. The signatures of these southern waters have been found at $62^{\circ} \mathrm{N}$ in the Atlantic (Elliot et al. 2002).

In the southern Atlantic, Indian, and Pacific Oceans as well as in the northern Atlantic, we found significant correlations between bottom property changes and volume transport changes. In the south basins, the decrease in bottom density was mainly associated with a decrease in the total AABW volume transport; in the North Atlantic, it was mainly associated with a decrease in the AMOC (Tables 3-5). AABW and NADW cells are both density driven; hence, it seems reasonable to assume that, if density changes, these transports are altered. Changes in transport in CMIP5 models 


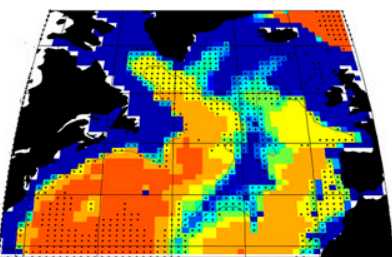

$36.9=37.17$

a) ACCESS1-0

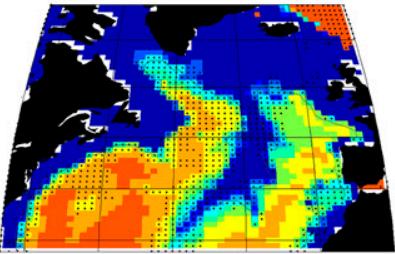

$37.12=37.26$

e) CESM1-CAM5

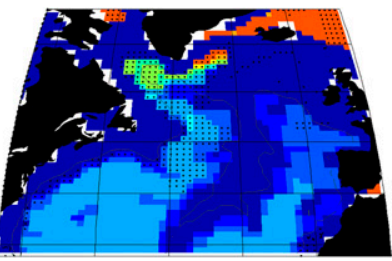

$37.2=37.3$

i) CSIRO-Mk3-6-0

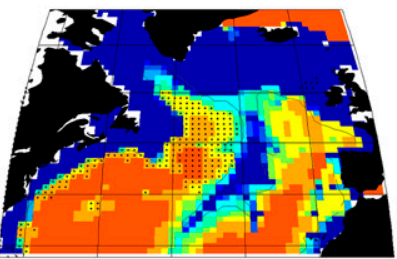

36.86 피 37.02

m) GFDL-ESM2M

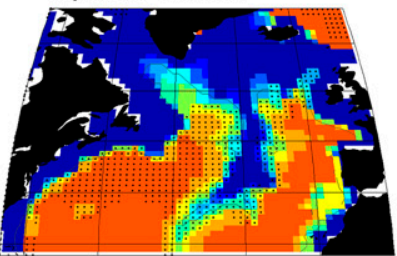

$36.94=37.1$

q) HadGEM2-ES

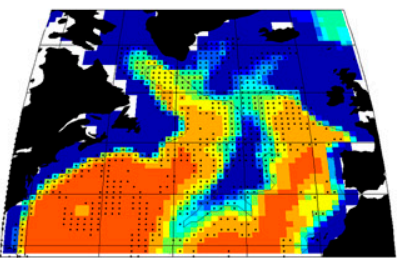

$\mathbf{3 7 . 0 4}=\mathbf{3 7 . 3}$

u) MIROC-ESM-CHEM

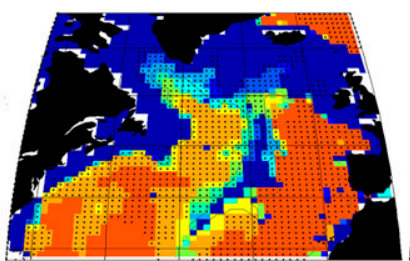

$36.76=36.96$

b) bcc-csm1-1

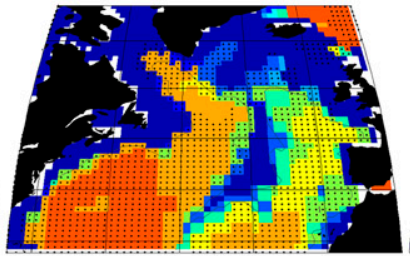

$36.9=37.06$

\section{f) $\mathrm{CMCC}-\mathrm{CM}$}

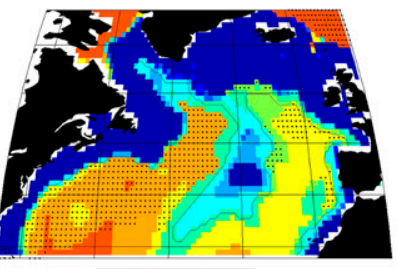

$37.06=37.27$

j) FGOALS-g2

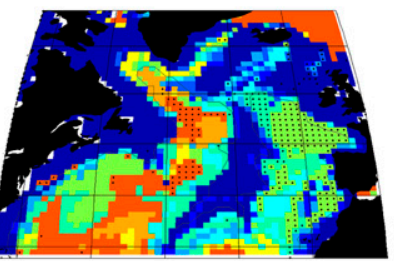

$37=37.15$

n) GISS-E2-H

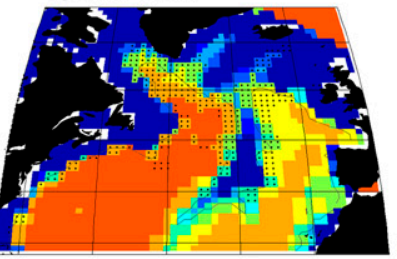

37.02 페 37.17

r) IPSL-CM5A-LR

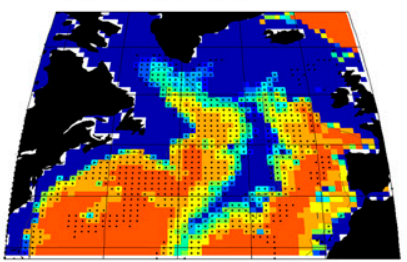

$36.82=37.02$

v) MPI-ESM-LR

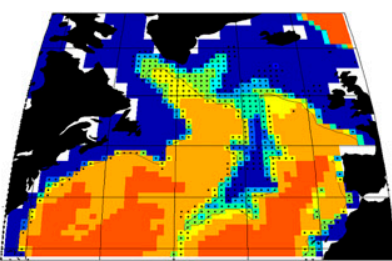

$37.1=37.3$

c) CanESM2

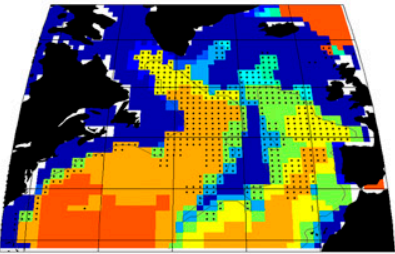

$36.9=37.06$

g) CMCC-CMS

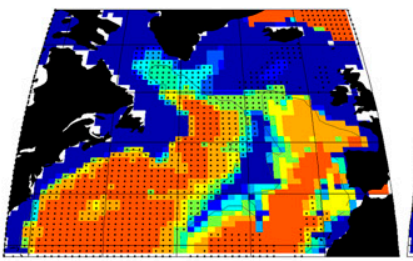

$36.81=37.01$

k) GFDL-CM3

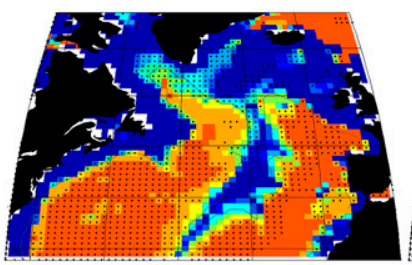

$36.7=37.21$

o) GISS-E2-R

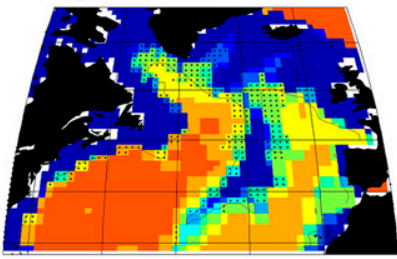

$37.03=37.18$

s) IPSL-CM5A-MR

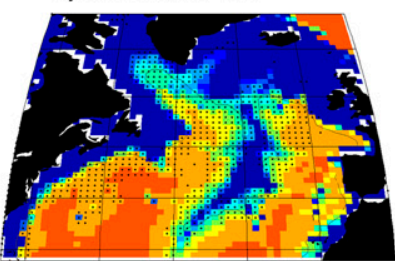

$\mathbf{3 6 . 8 7}=\mathbf{3 7 . 0 5}$

w) MPI-ESM-MR

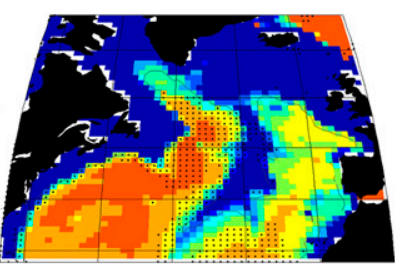

$37.12=37.26$

d) CCSM4

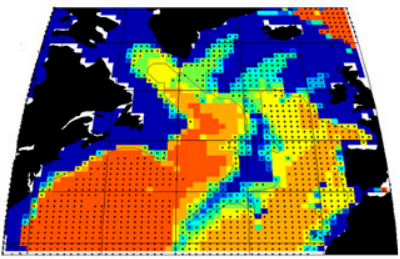

$36.82=37.06$

h) CNRM-CM5

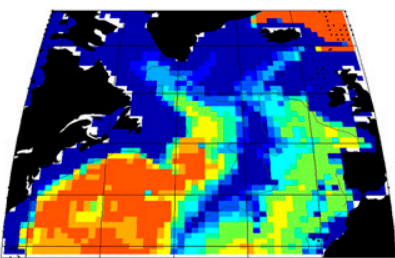

$\mathbf{3 7 . 0 7}=\mathbf{3 7 . 2 1}$

I) GFDL-ESM2G

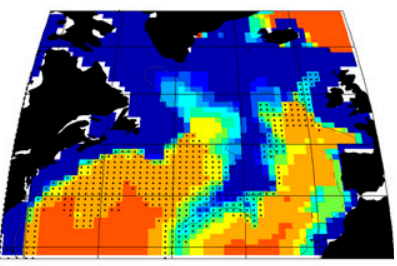

$36.95=37.12$

p) HadGEM2-CC

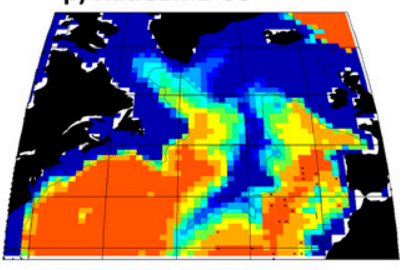

$36.9=37.05$

t) MIROC5

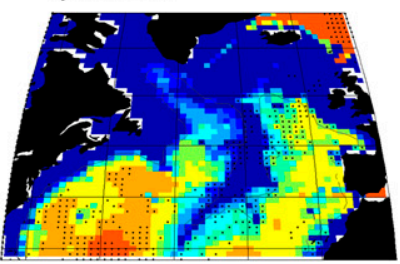

$37.1=37.4$

x) NorESM1-M

FIG. 13. North Atlantic $\left(25^{\circ}-70^{\circ} \mathrm{N}, 80^{\circ} \mathrm{W}-0^{\circ}\right)$ RCP8.5 (2081-2100) mean actual bottom density $\sigma_{2}$ for each model. Stippling indicates where the change of bottom density is positive. Gray contour is the $3000-\mathrm{m}$ isobath. 
have been found in relation to surface property changes (e.g., Jahn and Holland 2013) or intermediate depths changes (Schleussner et al. 2014). We found that future changes in density in the deep oceans too are linked with a weakening of bottom and deep water volume transports.

The decrease in bottom density of the global oceans will also result in steric mean global sea level rise. Bottom property changes by 2100 in RCP 8.5 climate change simulations lead to a multimodel average MGSLR of $3.8 \mathrm{~mm}$ for the $500 \mathrm{~m}$ at the bottom of the deep oceans, mainly because of the temperature changes (thermosteric contribution $=4.0 \mathrm{~mm}$; halosteric $=$ $-0.2 \mathrm{~mm}$ ). This value represents $1.4 \%$ of the projected MGSLR by 2100 due to thermal expansion through the whole depth of the oceans $(0.27 \pm 0.06 \mathrm{~m}$; Collins et al. 2014) for RCP8.5. It is lower than the current rate of change $\left(0.053 \mathrm{~mm} \mathrm{yr}^{-1}\right)$ observed by Purkey and Johnson (2010) for the abyssal oceans, but there is a large intermodel spread, notably because of the disagreement regarding bottom salinity changes. The largest MGSLR values are found for models whose bottom layer is globally warming and freshening (e.g., $22.7 \mathrm{~mm}$ for MIROC-ESMCHEM). The IPCC AR5 declared steric changes to be the main contributor to current and projected sea level rise. Kuhlbrodt and Gregory (2012) showed that the model spread in ocean vertical heat transport processes contributed significantly to the spread in thermosteric sea level rise projections in CMIP5 models; we show that it is key for reliable sea level rise projections that models also predict accurately the extent of deep and bottom property changes, probably by better representing deep and bottom water formation processes and volume transports.

More agreement among models can be reached if key common behaviors or differences are identified in CMIP5 models. The main structural difference between the models of our sample is their vertical coordinate system. Non- $z$-level models are underrepresented in CMIP5; hence, we do not have enough models from each type of system (Table 1) to thoroughly study the effect of each grid type. In fact, among our 25 models we have only one isopycnic model (GFDL-ESM2G), two hybrid $z$-isopycnic models (GISS-E2-H and NorESM1-M), one sigmalevel model (INM-CM4), two hybrid sigma $-z$ models (MIROC5 and MIROC-ESM-CHEM), and four geopotential $z^{*}$ models (FGOALS-g2, GFDL CM3, GFDL-ESM2M, and GISS-E2-R). We could only compare non- $z$-level models as a whole with $z$ levels. Regarding their 1986-2005 volume transport mean value or variability (Table 2), their volume transport change (Fig. 8), or their bottom property changes (Figs. 5-7), no notable difference was found between $z$-level models and the 10 non- $z$-level models. The small number of models from each coordinate type is probably the main reason preventing us from finding clear differences between the vertical coordinate systems.

Keeping the same ocean model code but changing the atmosphere code does impact the bottom water properties and abyssal transports. Comparing CCSM4 with CESM1 (CAM5); HadGEM2-CC with HadGEM2-ES; and ACCESS1.0, GFDL CM3, and GFDL-ESM2M together, the patterns of bottom property changes are very similar but not identical (Figs. 5-7). There is strong agreement regarding the sign of the change but disagreement on its extent: for example, in the North Atlantic. Likewise, although they agree on the sign of the volume transport change (Fig. 8), models with the same ocean code but different atmosphere codes have different 1986-2005 (Table 2) and climate change (Fig. 9) mean values of the transports, in particular AABW transport. For example the total SMOC is 3 times smaller in CESM1 (CAM5) than in CCSM4 and varies between 3, 8, and 14Sv for GFDL CM3, ACCESS1.0, and GFDL-ESM2M, respectively. If the ocean code is changed but the atmosphere code is the same (as is the case for GFDL-ESM2G and GFDL-ESM2M; GISSE2-H and GISS-E2-R; or ACCESS1.0, HadGEM2-CC, and HadGEM2-ES), no common behavior can be found. For example, GISS-E2-H projects a cooling of the Southern Ocean subpolar gyres which warm in GISS-E2-R, ACCESS1.0 agrees with both HadGEM2 variants in the Ross Sea but not in the Weddell Sea, and both GFDL-ESM2G and GFDL-ESM2M agree on a warming in this area (Fig. 5).

Increasing the horizontal resolution of the ocean model seems to increase the area of deep convection both in the North Atlantic (Fig. 11: models from CMCC, IPSL, and MPI) and in the Southern Ocean (Fig. 3). It also enhances the future decrease of this area: higher resolution models exhibit a greater decrease in the area of deep convection at both poles. Changing the horizontal resolution modifies the volume transport and the bottom property changes but not in a systematic way: the AMOC is the strongest for CMCC-CMS (low resolution), MPI-ESM-LR (low resolution), and IPSL-CM5A-MR (higher resolution); the historical $\mathrm{ACC}$ is the strongest for CMCC-CMS and IPSL-CM5A-LR, but it is stronger in MPI-ESM-MR than in MPI-ESM-LR. In summary, no consistent behavior could be found among models with similar vertical coordinate types, similar ocean and/or atmosphere codes, or increased resolutions. Here we worked only with one ensemble member for each model, mainly because most models provided 
only one ensemble member. For each model, more ensembles are needed to evaluate its biases and variability (Flato et al. 2014). Moreover, we saw that some fields for some models have a large drift or long-term variability in their preindustrial control run (see appendix). This drift can impact climate change studies, as it can erroneously suggest a significant trend in Earth's energy budget (Palmer and McNeall 2014).

\section{Conclusions}

We assessed the global ocean bottom temperature, salinity and density at the end of the twenty-first century (2081-2100) in two climate change scenarios (RCP4.5 and RCP8.5) compared with the end of the historical run (1986-2005) for 24 CMIP5 climate models. All models predict that the Southern Hemisphere deep basins will become warmer and lighter. All models agree on part of the North Atlantic getting colder and denser. Little agreement and no clear spatial patterns were found regarding salinity changes. In the Pacific and Indian Oceans, the warming signal is the strongest in the southern subpolar gyres (the area where models form their bottom water) and decreases northward. In the North and South Atlantic, the changes in bottom properties are largest at high latitudes.

The AMOC at $30^{\circ} \mathrm{N}$ weakens during the twenty-first century for most models and the weakening is enhanced in the strong warming scenario (RCP8.5). For most models, the change in the ACC transport is relatively small and insensitive to the forcing. The northward transport of AABW in the Pacific is the strongest (6 Sv for the RCP8.5 multimodel mean) and weakens by the end of the century for most models, with more weakening in RCP8.5 than in RCP4.5. The Atlantic and Indian AABW transports are lower (both around $2 \mathrm{~Sv}$ for the RCP8.5 multimodel mean). Little agreement was found among models regarding the sign of their change.

In each basin, changes in bottom properties and transports are linked. In the South Atlantic, Pacific, and Indian Oceans, the most intense warming of the bottom layer occurs for models with the strongest SMOC. The change in properties is the strongest in bottom water formation areas (in models) and is then transported northward. In the North Atlantic, bottom cooling and freshening are due to a decrease in deep convection, resulting in the intrusion of modified Antarctic Bottom Water from the south. In turn, all these changes in properties impact the transports; models with largest decrease in bottom density experience the strongest weakening in their transport.

The accurate representation of deep and bottom water transports in models is therefore key to predicting deep ocean heat storage and hence future sea level rise. Changes in properties for the bottom $500 \mathrm{~m}$ of the deep oceans correspond to a multimodel mean of $3.8-\mathrm{mm}$ steric MGSLR by 2100 . Knowing how changes in ocean properties propagate from bottom water formation sites to the remote deep basins, as well as the impact of the bottom property changes on their volume transport, will help better estimate the future warming of the deep oceans, sea level rise, and even atmospheric changes (Rose et al. 2014).

Acknowledgments. This work is funded by a NERC Open CASE PhD studentship award to UEA and the Met Office (RCUK NE/I018239/1). Jeff Ridley was supported by the Joint DECC/Defra Met Office Hadley Centre Climate Programme (GA01101). We acknowledge the World Climate Research Programme's Working Group on Coupled Modelling, which is responsible for CMIP, and we thank the climate modeling groups (whose models are listed in Table 1 of this paper) for producing and making available their model output. We thank A. Meijers, S. Griffies, and one anonymous reviewer for very useful comments, suggestions of extra analyses and encouragement. The research presented in this paper was carried out on the High Performance Computing Cluster supported by the Research and Specialist Computing Support service at the University of East Anglia, United Kingdom.

\section{APPENDIX}

\section{A Brief Comparison of the Climate Change Signal and the Model Drift in CanESM2, GFDL-ESM2G, and MIROC-ESM-CHEM}

Three CMIP5 models have been chosen to compare the magnitude of the climate change signal with the model drift, and check that the changes discussed in this manuscript are meaningful and not simply reflecting the preindustrial control run variability. The models, CanESM2, GFDL-ESM2G, and MIROC-ESM-CHEM, were chosen as they have distinct ocean vertical grid types (Table 1).

The three models have no drift in the transports, with the exception of the AMOC for GFDL-ESM2G, which has increased by $5 \mathrm{~Sv}$ by 2100 (Fig. A1). There is a large interannual, decadal, and multidecadal variability in the control run for all models and all transports. For the 

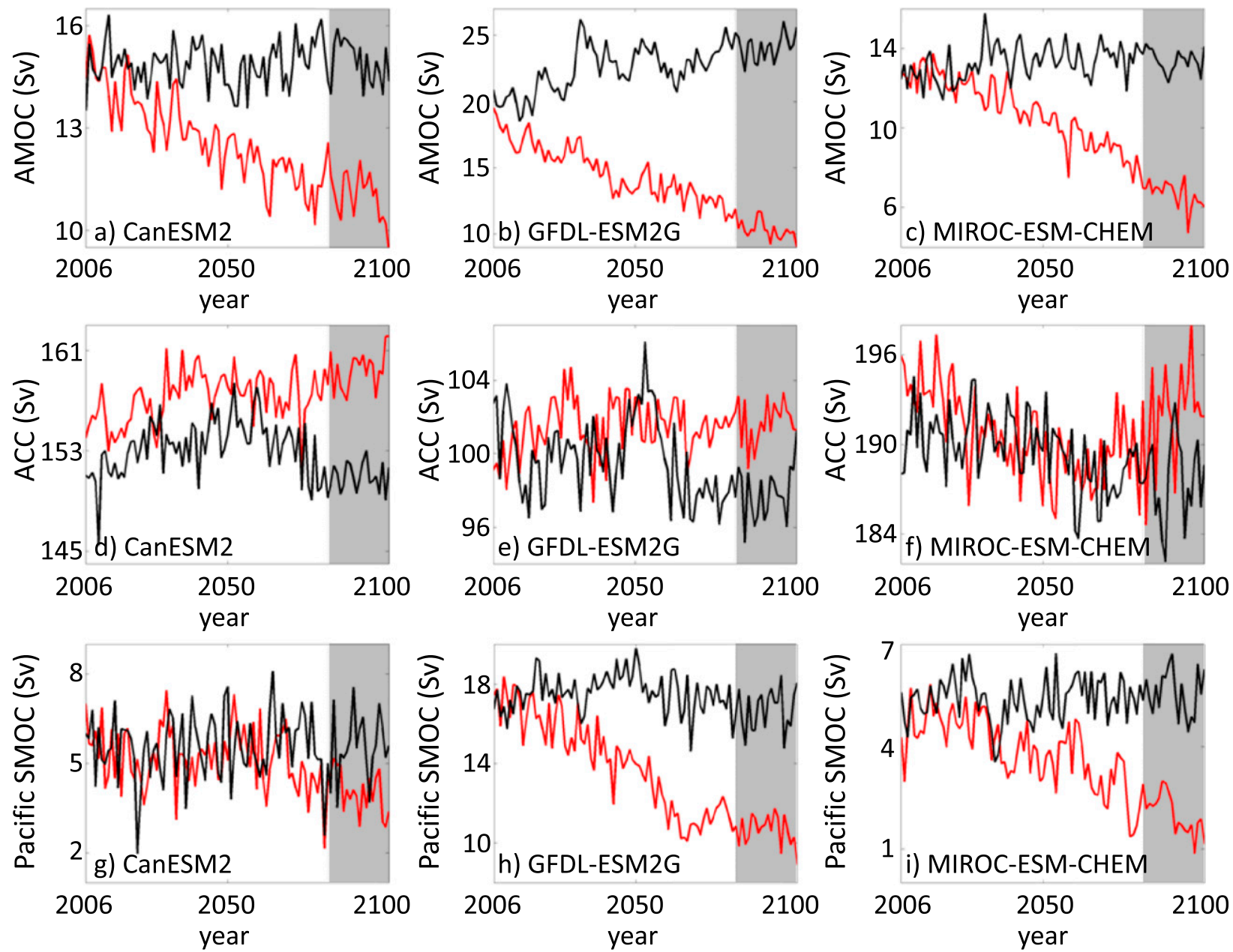

FIG. A1. Annual mean for 2006-2100, in RCP8.5 (red) and the preindustrial control (black), of the (top) AMOC, (middle) ACC, and (bottom) Pacific SMOC for (a),(d),(g) CanESM2; (b),(e),(h) GFDL-ESM2G; and (c),(f),(i) MIROC-ESM-CHEM. The period 2081-2100 studied in the text is shown in the gray box.

AMOC, the trend in the RCP8.5 run is fairly linear and unrelated to the model drift (Figs. A1a-c). The changes in AMOC fall outside the range of the variability of the model. The same can be said for the ACC in CanESM2 and GFDL-ESM2G from the 2070s (Figs. A1d,e), as well as for the Pacific SMOC for GFDL-ESM2G and MIROC-ESM-CHEM (Figs. A1h,i). For the ACC in MIROC-ESM-CHEM and the Pacific SMOC in CanESM2 (Figs. A1f,g), the trend in RCP8.5 and the model drift have the same magnitude; hence, the climate change signal in these cases is not significant. It has already been noted in section $3 \mathrm{~b}$ that the climate change signal falls within the range of internal variability.

For the bottom properties, three types of behaviors are possible (and are encountered in these models). The model can have some variability in its control run but no clear centennial trend (Figs. A2a,b,e,h). The control run can drift in the opposite direction from the climate change signal (Fig. A2g), or it can drift in the same direction as the climate change signal (Figs. A2c,d,f,i). In the latter case, we can further distinguish between the parameters and models whose climate change signal trend is larger than the drift (all bottom temperatures: e.g., Figs. A2c,i) and the models where the trend in climate change and the drift have the same magnitude (mostly bottom salinity: e.g., Figs. A2d,f). For most locations where drift and trend have the same magnitude, the signal with the drift removed was too weak to be considered significant and was not studied further (section 3a).

In summary, for the 12 models (indicated in Table 1) whose complete time series were obtained, particularly for these 3 models, the climate change signals 

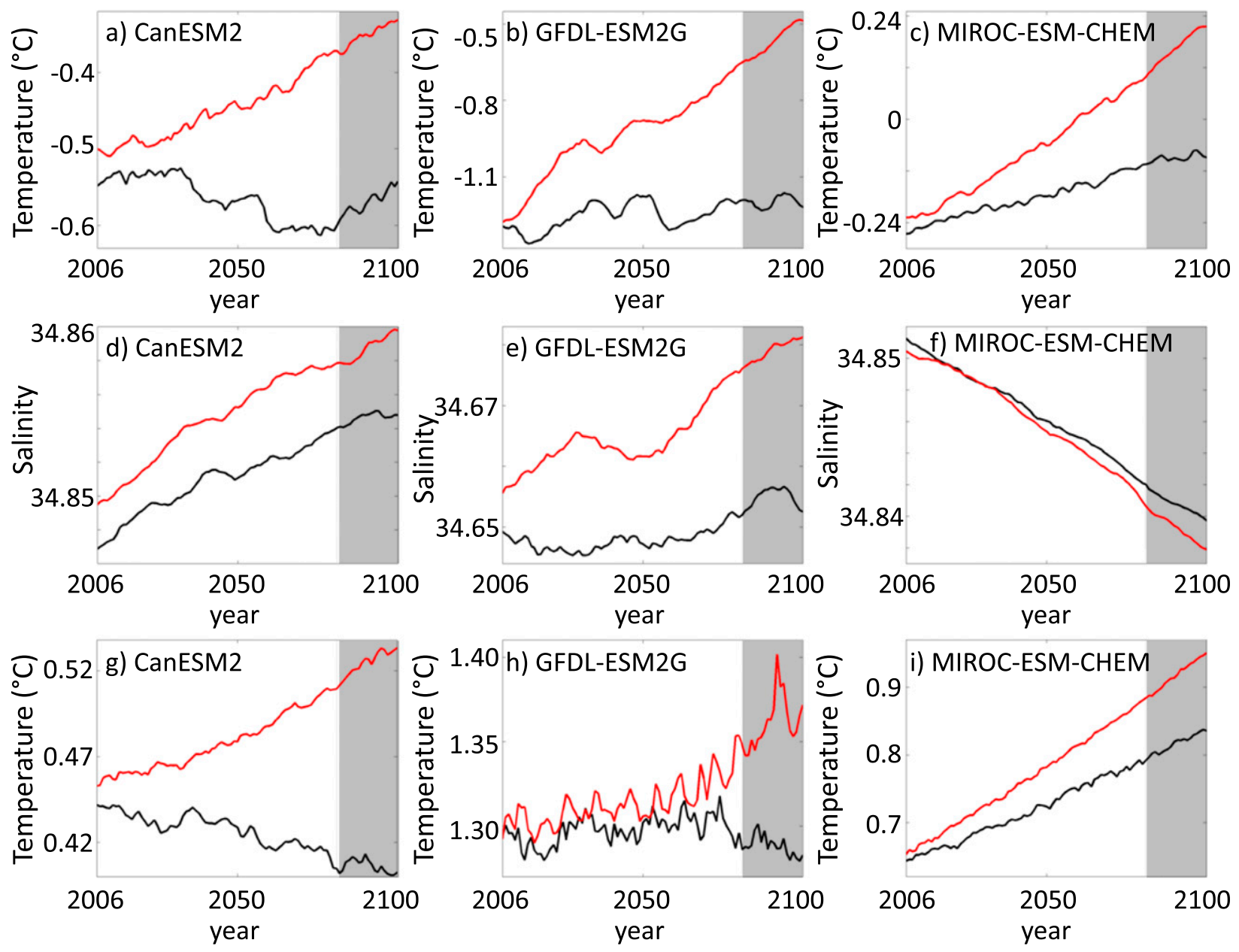

FIG. A2. Annual mean for 2006-2100, in RCP8.5 (red) and the preindustrial control (black), of (top) the bottom potential temperature in the Atlantic between $80^{\circ}$ and $60^{\circ} \mathrm{S}$, (middle) the bottom salinity in the Indian between $60^{\circ}$ and $30^{\circ} \mathrm{S}$, and (bottom) the bottom potential temperature in the Pacific between $30^{\circ}$ and $60^{\circ} \mathrm{N}$ for (a),(d),(g) CanESM2; (b),(e),(h) GFDL-ESM2G; and (c),(f),(i) MIROC-ESMCHEM. The period 2081-2100 studied in the text is shown in the gray box.

commented on in section 3 were found to be significant compared with the model drift. Looking at the drift, particularly its variability, confirms that averaging the outputs over a time longer than the decadal variability is necessary to ensure that the climate change signal is seen. This also highlights the need to remove the drift to obtain the actual model response to a warming atmosphere.

\section{REFERENCES}

Arora, V. K., and Coauthors, 2011: Carbon emission limits required to satisfy future representative concentration pathways of greenhouse gases. Geophys. Res. Lett., 38, L05805, doi:10.1029/2010GL046270.

Bi, D., and Coauthors, 2013: The ACCESS coupled model: Description, control climate and evaluation. Aust. Meteor. Ocean $J ., 63,41-64$.
Bindoff, N. L., and W. R. Hobbs, 2013: Oceanography: Deep ocean freshening. Nat. Climate Change, 3, 864-865, doi:10.1038/ nclimate2014.

Brix, H., and R. Gerdes, 2003: North Atlantic Deep Water and Antarctic Bottom Water: Their interaction and influence on the variability of the global ocean circulation. J. Geophys. Res., 108, 3022, doi:10.1029/2002JC001335.

Cheng, W., J. C. H. Chiang, and D. Zhang, 2013: Atlantic meridional overturning circulation (AMOC) in CMIP5 models: RCP and historical simulations. J. Climate, 26, 7187-7197, doi:10.1175/ JCLI-D-12-00496.1.

Coles, V. J., M. S. McCartney, D. B. Olson, and W. M. Smethie Jr., 1996: Changes in Antarctic Bottom Water properties in the western South Atlantic in the late 1980s. J. Geophys. Res., 101, 8957-8970, doi:10.1029/95JC03721.

Collins, M., and Coauthors, 2014: Long-term climate change: Projections, commitments and irreversibility. Climate Change 2013: The Physical Science Basis, T. F. Stocker et al., Eds., Cambridge University Press, 10291136. 
Danabasoglu, G., S. C. Bates, B. P. Briegleb, S. R. Jayne, M. Jochum, W. G. Large, S. Peacock, and S. G. Yeager, 2012: The CCSM4 ocean component. J. Climate, 25, 1361-1389, doi:10.1175/ JCLI-D-11-00091.1.

de Boyer Montégut, C., G. Madec, A. S. Fisher, A. Lazar, and D. Iudicone, 2004: Mixed layer depth over the global ocean: An examination of profile data and a profile-based climatology. J. Geophys. Res., 109, C12003, doi:10.1029/2004JC002378.

de Lavergne, C., J. B. Palter, E. D. Galbraith, R. Bernardello, and I. Marinov, 2014: Cessation of deep convection in the open Southern Ocean under anthropogenic climate change. Nat. Climate Change, 4, 278-282, doi:10.1038/nclimate2132.

Dickson, B., I. Yashayaev, J. Meincke, B. Turrell, S. Dye, and J. Holfort, 2002: Rapid freshening of the deep North Atlantic Ocean over the past four decades. Nature, 416, 832837, doi:10.1038/416832a.

Downes, S. M., and A. M. Hogg, 2013: Southern Ocean circulation and eddy compensation in CMIP5 models. J. Climate, 26, 7198-7220, doi:10.1175/JCLI-D-12-00504.1.

Drijfhout, S., G. J. van Oldenborgh, and A. Cimatoribus, 2012: Is a decline of AMOC causing the warming hole above the North Atlantic in observed and modeled warming patterns? J. Climate, 25, 8373-8379, doi:10.1175/JCLI-D-12-00490.1.

Dufour, C. O., J. Le Sommer, J. D. Zika, M. Gehlen, J. C. Orr, P. Mathiot, and B. Barnier, 2012: Standing and transient eddies in the response of the Southern Ocean meridional overturning to the southern annular mode. J. Climate, 25, 6958-6974, doi:10.1175/JCLI-D-11-00309.1.

Dufresne, J.-L., and Coauthors, 2013: Climate change projections using the IPSL-CM5 Earth System Model: From CMIP3 to CMIP5. Climate Dyn., 40, 2123-2165, doi:10.1007/s00382-012-1636-1.

Dunne, J. P., and Coauthors, 2012: GFDL's ESM2 global coupled climate-carbon Earth system models. Part I: Physical formulation and baseline simulation characteristics. J. Climate, 25, 6646-6665, doi:10.1175/JCLI-D-11-00560.1.

Elliot, M., L. Labeyrie, and J. C. Duplessy, 2002: Changes in North Atlantic deep-water formation associated with the DansgaardOeschger temperature oscillations (60-10 ka). Quat. Sci. Rev., 21, 1153-1165, doi:10.1016/S0277-3791(01)00137-8.

Fahrbach, E., M. Hoppema, G. Rohardt, M. Schröder, and A. Wisotzki, 2004: Decadal-scale variations of water mass properties in the deep Weddell Sea. Ocean Dyn., 54, 77-91, doi:10.1007/s10236-003-0082-3.

Flato, G., and Coauthors, 2014: Evaluation of climate models. Climate Change 2013: The Physical Science Basis, T. F. Stocker et al., Eds., Cambridge University Press, 741-866.

Fofonoff, N. P., and R. C. Millard, 1983: Algorithms for computation of fundamental properties of seawater. UNESCO Marine Science Tech. Paper 44, 58 pp.

Fogli, P. G., and Coauthors, 2009: INGV-CMCC carbon (ICC): A carbon cycle Earth system model. CMCC Research Paper 61, $31 \mathrm{pp}$.

Gordon, H. B., S. P. O'Farrell, M. A. Collier, M. R. Dix, L. D. Rotstayn, E. A. Kowalczyk, A. C. Hirst, and I. G. Watterson, 2010: The CSIRO Mk3.5 climate model. CAWCR Tech. Rep. $21,74 \mathrm{pp}$.

Griesel, A., M. R. Mazloff, and S. T. Gille, 2012: Mean dynamic topography in the Southern Ocean: Evaluating Antarctic Circumpolar Current transport. J. Geophys. Res., 117, C01020, doi:10.1029/2011JC007573.

Griffies, S. M., and Coauthors, 2011: The GFDL CM3 coupled climate model: Characteristics of the ocean and sea ice simulations. J. Climate, 24, 3520-3544, doi:10.1175/2011JCLI3964.1.
Hellmer, H. H., O. Huhn, D. Gomis, and R. Timmermann, 2011: On the freshening of the northwestern Weddell Sea continental shelf. Ocean Sci., 7, 305-316, doi:10.5194/os-7-305-2011.

Heuzé, C., K. J. Heywood, D. P. Stevens, and J. K. Ridley, 2013: Southern Ocean bottom water characteristics in CMIP5 models. Geophys. Res. Lett., 40, 1409-1414, doi:10.1002/ $\operatorname{grl} .50287$.

Huussen, T. N., A. C. Naveira-Garabato, H. L. Bryden, and E. L. McDonagh, 2012: Is the deep Indian Ocean MOC sustained by breaking internal waves? J. Geophys. Res., 117, C08024, doi:10.1029/2012JC008236.

Jahn, A., and M. M. Holland, 2013: Implications of Arctic sea ice changes for North Atlantic deep convection and the meridional overturning circulation in CCSM4 CMIP5 simulations. Geophys. Res. Lett., 40, 1206-1211, doi:10.1002/grl.50183.

Jia, Y., 2003: Ocean heat transport and its relationship to ocean circulation in the CMIP coupled models. Climate Dyn., 20, 153-174, doi:10.1007/s00382-002-0261-9.

Johnson, G. C., 2008: Quantifying Antarctic Bottom Water and North Atlantic Deep Water volumes. J. Geophys. Res., 113, C05027, doi:10.1029/2007JC004477.

—, S. Mecking, B. M. Sloyan, and S. E. Wijffels, 2007: Recent Bottom Water warming in the Pacific Ocean. J. Climate, 20, 5365-5375, doi:10.1175/2007JCLI1879.1.

Jones, C. D., and Coauthors, 2011: The HadGEM2-ES implementation of CMIP5 centennial simulations. Geosci. Model Dev., 4, 543-570, doi:10.5194/gmd-4-543-2011.

Jullion, L., A. C. Naveira-Garabato, M. P. Meredith, P. R. Holland, P. Courtois, and B. A. King, 2013: Decadal freshening of the Antarctic Bottom Water exported from the Weddell Sea. J. Climate, 26, 8111-8125, doi:10.1175/JCLI-D-12-00765.1.

Jungclaus, J. H., and Coauthors, 2013: Characteristics of the ocean simulations in the Max Planck Institute Ocean Model (MPIOM) the ocean component of the MPI-Earth system model. J. Adv. Model. Earth Syst., 5, 422-446, doi:10.1002/ jame.20023.

Killworth, P. D., 1983: Deep convection in the world ocean. Rev. Geophys., 21, 1-26, doi:10.1029/RG021i001p00001.

Kuhlbrodt, T., and J. M. Gregory, 2012: Ocean heat uptake and its consequences for the magnitude of sea level rise and climate change. Geophys. Res. Lett., 39, L18608, doi:10.1029/ 2012GL052952.

Lee, M. M., D. P. Marshall, and R. G. Williams, 1997: On the eddy transfer of tracers: Advective or diffusive? J. Mar. Res., 55, 483-505, doi:10.1357/0022240973224346.

Levitus, S., J. I. Antonov, T. P. Boyer, and C. Stephens, 2000: Warming of the world ocean. Science, 287, 2225-2229, doi:10.1126/ science.287.5461.2225.

Liu, H. L., P. F. Lin, Y. Q. Yu, and X. H. Zhang, 2012: The baseline evaluation of LASG/IAP Climate System Ocean Model (LICOM) version 2.0. Acta Meteor. Sin., 26,318-329, doi:10.1007/ s13351-012-0305-y.

Lumpkin, R., and K. Speer, 2007: Global Ocean meridional overturning. J. Phys. Oceanogr., 37, 2550-2562, doi:10.1175/JPO3130.1.

Martin, T., W. Park, and M. Latif, 2013: Multi-centennial variability controlled by Southern Ocean convection in the Kiel Climate Model. Climate Dyn., 40, 2005-2022, doi:10.1007/ s00382-012-1586-7.

Meijers, A. J. S., 2014: The Southern Ocean in the Coupled Model Intercomparison Project phase 5. Philos. Trans. Roy. Soc., 372A, doi:10.1098/rsta.2013.0296.

, E. Shuckburgh, N. Bruneau, J.-B. Sallée, T. J. Bracegirdle, and Z. Wang, 2012: Representation of the Antarctic Circumpolar 
Current in the CMIP5 climate models and future changes under warming scenarios. J. Geophys. Res., 117, C12008, doi:10.1029/ 2012JC008412.

Mignot, J., A. Ganopolski, and A. Levermann, 2007: Atlantic subsurface temperatures: Response to a shutdown of the overturning circulation and consequences for its recovery. J. Climate, 20, 4884-4898, doi:10.1175/JCLI4280.1.

Palmer, M. D., and D. J. McNeall, 2014: Internal variability of Earth's energy budget simulated by CMIP5 climate models. Environ. Res. Lett., 9, 034016, doi:10.1088/1748-9326/9/3/034016.

Purkey, S. G., and G. C. Johnson, 2010: Warming of global abyssal and deep Southern Ocean waters between the 1990s and 2000s: Contributions to global heat and sea level rise budgets. J. Climate, 23, 6336-6351, doi:10.1175/2010JCLI3682.1.

Rayner, N. A., D. E. Parker, E. B. Horton, C. K. Folland, L. V. Alexander, D. P. Rowell, E. C. Kent, and A. Kaplan, 2003: Global analyses of sea surface temperature, sea ice, and night marine air temperature since the late nineteenth century. J. Geophys. Res., 108, 4407, doi:10.1029/2002JD002670.

Rintoul, S. R., 2007: Rapid freshening of Antarctic Bottom Water formed in the Indian and Pacific Oceans. Geophys. Res. Lett., 34, L06606, doi:10.1029/2006GL028550.

Rose, B. E., K. C. Armour, D. S. Battisti, N. Feldl, and D. D. Koll, 2014: The dependence of transient climate sensitivity and radiative feedbacks on the spatial pattern of ocean heat uptake. Geophys. Res. Lett., 41, 1071-1078, doi:10.1002/2013GL058955.

Sallée, J.-B., E. Shuckburgh, N. Bruneau, A. J. S. Meijers, T. J. Bracegirdle, Z. Wang, and T. Roy, 2013: Assessment of Southern Ocean water mass circulation and characteristics in CMIP5 models: Historical bias and forcing response. J. Geophys. Res. Oceans, 118, 1830-1844, doi:10.1002/jgrc.20135.

Schleussner, C. F., J. Runge, J. Lehmann, and A. Levermann, 2014: The role of the North Atlantic overturning and deep ocean for multi-decadal global-mean-temperature variability. Earth Syst. Dyn., 5, 103-115, doi:10.5194/esd-5-103-2014.

Schmidt, G. A., and Coauthors, 2006: Present-day atmospheric simulations using GISS ModelE: Comparison to in situ, satellite, and reanalysis data. J. Climate, 19, 153-192, doi:10.1175/ JCLI3612.1.

Sloyan, B. M., and S. R. Rintoul, 2001: The Southern Ocean limb of the global deep overturning circulation. J. Phys. Oceanogr., 31, 143173, doi:10.1175/1520-0485(2001)031<0143:TSOLOT $>2.0$.CO;2.
Srokosz, M., M. Baringer, H. Bryden, S. Cunningham, T. Delworth, S. Lozier, J. Marotzke, and R. Sutton, 2012: Past, present, and future changes in the Atlantic meridional overturning circulation. Bull. Amer. Meteor. Soc., 93, 1663-1676, doi:10.1175/ BAMS-D-11-00151.1.

Stocker, T. F., and Coauthors, Eds., 2014: Climate Change 2013: The Physical Science Basis. Cambridge University Press, $1535 \mathrm{pp}$.

Swingedouw, D., T. Fichefet, H. Goosse, and M. F. Loutre, 2009: Impact of transient freshwater releases in the Southern Ocean on the AMOC and climate. Climate Dyn., 33, 365-381, doi:10.1007/ s00382-008-0496-1.

Taylor, K. E., R. J. Stouffer, and G. A. Meehl, 2012: An overview of CMIP5 and the experiment design. Bull. Amer. Meteor. Soc., 93, 485-498, doi:10.1175/BAMS-D-11-00094.1.

Tjiputra, J. F., M. Bentsen, C. Roelandt, J. Schwinger, and C. Heinze, 2013: Evaluation of the carbon cycle components in the Norwegian Earth System Model (NorESM). Geosci. Model Dev., 6, 301-325, doi:10.5194/gmd-6-301-2013.

Våge, K., and Coauthors, 2009: Surprising return of deep convection to the subpolar North Atlantic Ocean in winter 20072008. Nat. Geosci., 2, 67-72, doi:10.1038/ngeo382.

Voldoire, A., and Coauthors, 2013: The CNRM-CM5.1 global climate model: Description and basic evaluation. Climate Dyn., 40, 2091-2121, doi:10.1007/s00382-011-1259-y.

Volodin, E. M., N. A. Dianskii, and A. V. Gusev, 2010: Simulating present day climate with the INMCM4.0 coupled model of the atmospheric and oceanic general circulations. Izv. Atmos. Oceanic Phys., 46, 414-431, doi:10.1134/S000143381004002X.

Wang, Z., 2013: On the response of Southern Hemisphere subpolar gyres to climate change in coupled climate models. J. Geophys. Res. Oceans, 118, 1070-1086, doi:10.1002/jgrc.20111.

Watanabe, S., and Coauthors, 2011: MIROC-ESM 2010: Model description and basic results of CMIP5-20c3m experiments. Geosci. Model Dev., 4, 845-872, doi:10.5194/gmd-4-845-2011.

Xin, X. G., T. W. Wu, J. L. Li, Z. Wang, W. Li, and F. Wu, 2013: How well does BCC-CSM1.1 reproduce the 20th century climate change over China. Atmos. Oceanic Sci. Lett., 1, 21-26.

Yin, J., J. T. Overpeck, S. M. Griffies, A. Hu, J. L. Russell, and R. J. Stouffer, 2011: Different magnitudes of projected subsurface ocean warming around Greenland and Antarctica. Nat. Geosci., 4, 524-528, doi:10.1038/ngeo1189. 